\title{
Contributions of Diverse Excitatory and Inhibitory Neurons to Recurrent Network Activity in Cerebral Cortex
}

\author{
Garrett T. Neske, Saundra L. Patrick, and Barry W. Connors \\ Department of Neuroscience, Brown University, Providence, Rhode Island 02912
}

\begin{abstract}
The recurrent synaptic architecture of neocortex allows for self-generated network activity. One form of such activity is the Up state, in which neurons transiently receive barrages of excitatory and inhibitory synaptic inputs that depolarize many neurons to spike threshold before returning to a relatively quiescent Down state. The extent to which different cell types participate in Up states is still unclear. Inhibitory interneurons have particularly diverse intrinsic properties and synaptic connections with the local network, suggesting that different interneurons might play different roles in activated network states. We have studied the firing, subthreshold behavior, and synaptic conductances of identified cell types during Up and Down states in layers 5 and 2/3 in mouse barrel cortex in vitro. We recorded from pyramidal cells and interneurons expressing parvalbumin (PV), somatostatin (SOM), vasoactive intestinal peptide (VIP), or neuropeptide Y. PV cells were the most active interneuron subtype during the Up state, yet the other subtypes also received substantial synaptic conductances and often generated spikes. In all cell types except PV cells, the beginning of the Up state was dominated by synaptic inhibition, which decreased thereafter; excitation was more persistent, suggesting that inhibition is not the dominant force in terminating Up states. Compared with barrel cortex, SOM and VIP cells were much less active in entorhinal cortex during Up states. Our results provide a measure of functional connectivity of various neuron types in barrel cortex and suggest differential roles for interneuron types in the generation and control of persistent network activity.
\end{abstract}

Key words: barrel cortex; entorhinal cortex; inhibition; interneuron; slice; Up state

\section{Introduction}

A core feature of neocortex is its recurrent synaptic architecture. Cortical neurons are densely innervated, and the majority of their synapses arise from neighboring cortical neurons (Braitenburg and Shuz, 1998). This architecture allows the cortex to engage in self-generated and self-sustained network activation, which has functional implications for context-dependent sensory processing (Petersen et al., 2003; Haider et al., 2007; Hasenstaub et al., 2007), attention (Reynolds et al., 2000), and working memory (Goldman-Rakic, 1995). Furthermore, the spatiotemporal structure of sensory-evoked responses in cortex is quite similar to that of nondriven, spontaneous activity (Luczak et al., 2009), suggesting that recurrent circuitry largely controls cortical operations. Considering the primacy of recurrent network activity, it is important to elucidate the mechanisms involved in its generation, persistence, and termination.

Interposed within the excitatory cortical network are inhibitory interneurons, which play indispensable roles in the modulation of cortical activity. Interneurons have highly diverse intrinsic

\footnotetext{
Received June 4, 2014; revised Nov. 20, 2014; accepted Nov. 25, 2014.

Author contributions: G.T.N. and B.W.C. designed research; G.T.N. and S.L.P. performed research;G.T.N. analyzed data; G.T.N. and B.W.C. wrote the paper.

This work was supported by National Institutes of Health Grants NS-050434, MH-086400, and T32NS062443, and by DARPA-BAA-09-27.

The authors declare no competing financial interests.

Correspondence should be addressed to Dr. Barry W. Connors, Department of Neuroscience, Box GL-N, Division of Biology and Medicine, Brown University, Providence, Rl 02912. E-mail: BC@brown.edu.

DOI:10.1523/JNEUROSCI.2279-14.2015

Copyright $\odot 2015$ the authors $\quad 0270-6474 / 15 / 351089-17 \$ 15.00 / 0$
}

and synaptic physiology (Markram et al., 2004; Fishell and Rudy, 2011), and it has long been assumed that different interneuron subtypes play different roles in cortical operations. While the classification of interneuron subtypes is still debated, the neurochemical markers they express provide a practical way to identify them (Taniguchi et al., 2011).

To decipher the operational roles of different cell types, it is important to study their behavior during natural network states. In the absence of significant sensory drive or neuromodulation, cortical activity is characterized by slow $(<1 \mathrm{~Hz})$ cycles of the local field potential coincident with periods of depolarization and hyperpolarization of individual neurons (Wilson and Groves, 1981; Steriade et al., 1993; Sanchez-Vives and McCormick, 2000). These cycles are known as Up and Down states, respectively. Up states occur during anesthesia, slow-wave sleep, quiet wakefulness, and in slice preparations under specific conditions. Activity of neurons during the Up state itself also shares many similarities with the awake, "activated" cortex (Destexhe et al., 2007). Thus, Up and Down states constitute a valuable model for studying the mechanisms of dynamic modulations in cortical network activity.

Here we characterize the firing, subthreshold dynamics, and synaptic inputs of excitatory and inhibitory cells in layers 5 and $2 / 3$ of mouse barrel cortex during Up and Down states in vitro. In addition to pyramidal cells, we studied four neurochemically defined inhibitory interneurons expressing parvalbumin (PV), somatostatin (SOM), vasoactive intestinal peptide (VIP), and neuropeptide Y (NPY). We found that, whereas fast spiking (FS) PV cells were the most active interneuron subtype during the Up state, other 
subtypes also received substantial excitatory and inhibitory synaptic conductances and often spiked. By comparing barrel cortex with entorhinal cortex, we discovered that the contributions of inhibitory interneurons can differ substantially with cortical area. Our results suggest specific roles for various excitatory and inhibitory cell types in controlling sustained network activation.

\section{Materials and Methods}

Mouse lines. To target different interneuron subtypes for recording, we used four different mouse lines that expressed fluorescent protein under interneuron-specific promoters. To target PV, SOM, and VIP cells, we crossed respective homozygous Cre mice (PV-Cre: B6;129P2-

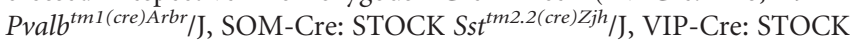
$V i p^{t m 1(c r e) Z j h} /$ J, The Jackson Laboratory) with the homozygous tdTo-

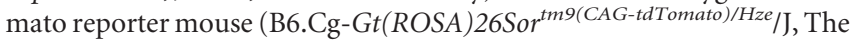
Jackson Laboratory). Progeny of these crosses expressed the red fluorescent protein tdTomato in PV, SOM, or VIP cells. To target NPY cells, we crossed a hemizygous transgenic NPY-GFP line (B6.FVB-Tg(NpyhrGFP)1Lowl/J, The Jackson Laboratory) with wild-type mice of the same genetic background (C57BL/6J, The Jackson Laboratory). We initially crossed one of the available NPY-Cre lines (STOCK Tg(Npycre)RH26Gsat/Mmucd, MMRRC) with the tdTomato reporter but found expression of tdTomato in cell types that should not express NPY in adult animals (e.g., pyramidal cells). Thus, crosses with the NPY-Cre line were discontinued.

Slice preparation. The procedure for preparing brain slices was approved by the Brown University Institutional Animal Care and Use Committee. Slices (320-400 $\mu \mathrm{m}$ ) were prepared from mouse barrel cortex (mice of both sexes aged P14-P19). Mice were first anesthetized via inhalation of isofluorane, then decapitated with a scalpel blade, after which the head was transferred to ice-cold $\left(\sim 0^{\circ} \mathrm{C}\right)$ artificial CSF (ACSF) saturated with a $95 \% \mathrm{O}_{2} / 5 \% \mathrm{CO}_{2}$ mixture for brain extraction. The composition of this ACSF was as follows (in $\mathrm{mm}$ ): $125 \mathrm{NaCl}, 2.5 \mathrm{KCl}, 25$ dextrose, $25 \mathrm{NaHCO}_{3}, 1.25 \mathrm{NaH}_{2} \mathrm{PO}_{4}, 1 \mathrm{CaCl}_{2}, 5 \mathrm{MgSO}_{4}$, and $2 \mathrm{Na}$ pyruvate. A mid-sagittal cut was made, and one hemisphere was glued on an angled block to cut slices in the thalamocortical plane for barrel cortex (Agmon and Connors, 1991) with a Leica VT 1000S vibratome. ACSF temperature was $\sim 0^{\circ} \mathrm{C}$ throughout slicing. After slices were cut, they were immediately transferred to a submerged holding chamber maintained at $\sim 33^{\circ} \mathrm{C}$, containing ACSF of the same composition as the cutting solution. The slices remained at this temperature and in this ACSF for $30 \mathrm{~min}$ before the chamber was cooled to room temperature $\left(\sim 24^{\circ} \mathrm{C}\right.$ ), while the ACSF was changed to the following composition (in $\mathrm{mm}): 126 \mathrm{NaCl}, 3 \mathrm{KCl}, 10$ dextrose, $26 \mathrm{NaHCO}_{3}, 1.25 \mathrm{NaH}_{2} \mathrm{PO}_{4}, 2 \mathrm{CaCl}_{2}$, and $2 \mathrm{MgSO}_{4}$. Slices remained at this temperature and in this solution until use in the recording chamber.

Electrophysiological recordings. Slices were transferred to a recording chamber in which ACSF bathed both sides of the slice (Warner Instruments, model RC-27 L). To promote Up and Down states, the flow rate of ACSF was kept high $(\sim 10 \mathrm{ml} / \mathrm{min})$ to ensure ample oxygenation of the tissue (Hájos and Mody, 2009; Hájos et al., 2009). The temperature of the solution in the recording chamber was $33^{\circ} \mathrm{C}$. In between recording sessions, slices were superfused with ACSF of the same composition as the final solution in the holding chamber. During recordings of Up and Down states, the ACSF was changed to (in $\mathrm{mm}$ ) as follows: $126 \mathrm{NaCl}, 5$ $\mathrm{KCl}, 20$ dextrose, $26 \mathrm{NaHCO}_{3}, 1.25 \mathrm{NaH}_{2} \mathrm{PO}_{4}, 1 \mathrm{CaCl}_{2}$, and $1 \mathrm{MgSO}_{4}$. Spontaneous Up and Down states usually occurred within $1 \mathrm{~min}$ of changing the superfusing solution. Up states were also evoked electrically with a twisted bipolar electrode (FHC) in layer 5, controlled by a stimulus isolation unit (Cygnus SIU-91). Stimulation was of the lowest intensity that reliably evoked recurrent network activity (5-30 $\mu \mathrm{A}$, pulse width $400 \mu \mathrm{s}$ ).

Cells were visualized with an Olympus BX50WI microscope equipped with DIC and epifluorescence optics. Different interneuron subtypes were targeted based on their fluorescence (see Mouse lines), and pyramidal cells were targeted based on their characteristic appearance with DIC optics (i.e., upward somatic taper and apical dendrite).
Whole-cell recordings were performed with borosilicate glass pipettes pulled to final tip resistances between 4 and $7 \mathrm{~m} \Omega$. For current-clamp recordings, micropipettes were filled with internal solution of the following composition (in $\mathrm{mM}$ ): $130 \mathrm{~K}$ gluconate, $4 \mathrm{KCl}, 2 \mathrm{NaCl}, 10 \mathrm{HEPES}, 0.2 \mathrm{EGTA}, 4$ ATP-Mg, 0.3 GTP-Na, and 14 phosphocreatine- $2 \mathrm{~K}$. For voltage-clamp recordings, micropipettes were filled with (in $\mathrm{mM}$ ) as follows: $130 \mathrm{Cs}$ gluconate, $4 \mathrm{CsCl}, 2 \mathrm{NaCl}, 10$ HEPES, 0.2 EGTA, 4 ATP-Mg, 0.3 GTP-Na, 14 phosphocreatine-2Na, and $5 \mathrm{QX}-314$. Internal solutions had a final osmolality of 290-295 mOsm and $\mathrm{pH}$ of 7.22-7.25. Recordings were made with a MultiClamp 700B patch-clamp amplifier (Axon), in which signals were first filtered (DC-10 kHz) and then digitized at $20 \mathrm{kHz}$ with the Digidata $1440 \mathrm{~A}$ data acquisition system and Clampex data acquisition software (Axon). Micropipette capacitance was compensated in the bath, and the bridge was balanced after attaining the whole-cell configuration. Cells with bridgebalance values $>30 \mathrm{M} \Omega$ were not used. For voltage-clamp recordings, series resistance compensation was always performed online, with prediction/correction set between $70 \%$ and $80 \%$. Series resistances were continually monitored during experiments to ensure sufficient compensation.

Data analysis. The following intrinsic cellular properties were measured: resting membrane potential, input resistance, spike threshold, membrane time constant, and action potential half-width. All intrinsic properties were measured before superfusing with the modified ACSF. Voltages were not corrected for the liquid junction potential, which has been measured as $14 \mathrm{mV}$ (Cruikshank et al., 2007). Resting potential was the membrane potential of the cell after attaining the whole-cell configuration without any injected current. Input resistance was calculated from the slope of the I-V curve using small, hyperpolarizing current pulses $(-150$ to $-50 \mathrm{pA})$. Spike threshold was calculated as the voltage at which $\mathrm{dV} / \mathrm{dt}$ first exceeded $5 \mathrm{~V} / \mathrm{s}$ during spiking with near-threshold depolarizing current steps. The membrane time constant was calculated by fitting a single exponential to the first $100 \mathrm{~ms}$ of the voltage response to a small hyperpolarizing current pulse, omitting the first $1 \mathrm{~ms}$. Action potential halfwidth was calculated as the width at half-height (measured from spike threshold) of spikes triggered by near-threshold depolarizing current.

Spontaneous and evoked Up states were detected by first visually inspecting voltage or current traces that contained Up states. Regions of the voltage trace that contained Up states were selected for further analysis. These regions included the Up state and $\sim 500 \mathrm{~ms}$ before and after the Up state. The times of Up state initiation and termination were determined from an algorithm described by Seamari et al., 2007 (our Fig. 3A). Briefly, an Up state was considered to have initiated when a "fast" exponential moving average computed on the trace crossed and remained above a "slow" exponential moving average for at least $200 \mathrm{~ms}$. An Up state was considered to have terminated when the "fast" exponential moving average crossed and remained below the "slow" exponential moving average for at least $400 \mathrm{~ms}$. The smoothing constant for the "fast" and "slow" exponential moving average was $5 \times 10^{-4}$ and $5 \times 10^{-6}$, respectively. In cases in which this algorithm gave ambiguous results about the Up state transitions, an alternative method was used, in which a running SD with a window of $50 \mathrm{~ms}$ was computed on the traces. The initiation of the Up state was then taken as the point at which the SD increased to $2 \times$ the baseline value and remained above this threshold for at least $200 \mathrm{~ms}$, whereas the termination of the Up state was taken as the point at which the SD remained below the threshold for at least $400 \mathrm{~ms}$.

For the calculation of mean time-dependent firing rates during Up states, the time-dependent firing rate for each Up state during a recording was first calculated as follows:

$$
R(t)=\sum_{i=1}^{n} w\left(t-t_{i}\right)
$$

where $t_{i}$ indicates the times at which a spike occurred for $n$ spikes in an Up state, and $w$ is a sliding Gaussian window,

$$
w(\tau)=\frac{1}{\sqrt{2 \pi} \sigma_{w}} \exp \left(-\frac{\tau^{2}}{2 \sigma_{w}^{2}}\right)
$$

where $\sigma_{\mathrm{w}}=10 \mathrm{~ms}$. The time-dependent firing rate $R(t)$ was then normalized in time so that $t$ runs from 0 to 1 . This was done to allow averaging of Up states across cells because Up state duration varied from 
Table 1. Up state durations in cell types and layers ${ }^{a}$

\begin{tabular}{llllllllll}
\hline & $\begin{array}{l}\text { L5 Pyr (RS) } \\
(n=28)\end{array}$ & $\begin{array}{l}\text { L5 Pyr (IB) } \\
(n=3)\end{array}$ & $\begin{array}{l}\text { L2/3 Pyr } \\
(n=73)\end{array}$ & $\begin{array}{l}\text { L5 PV } \\
(n=21)\end{array}$ & $\begin{array}{l}\text { L2/3 PV } \\
(n=18)\end{array}$ & $\begin{array}{l}\text { L5 SOM } \\
(n=25)\end{array}$ & $\begin{array}{l}\text { L2/3 SOM } \\
(n=32)\end{array}$ & $\begin{array}{l}\text { L2/3 VIP } \\
(n=23)\end{array}$ & $\begin{array}{l}\text { L2/3 NPY } \\
(n=16)\end{array}$ \\
\hline Mean (s) & 1.85 & 1.31 & 1.32 & 1.59 & 0.96 & 2.03 & 1.24 & 2.03 \\
Median (s) & 1.73 & 1.41 & 1.08 & 1.57 & 0.89 & 1.70 & 0.91 & 1.72 \\
SD (s) & 0.95 & 0.41 & 1.01 & 0.93 & 0.47 & 1.18 & 1.06 & 1.10 & 0.71 \\
\hline
\end{tabular}

${ }^{a}$ Significant differences were found in the following comparisons: L2/3 pyramidal versus L2/3 VIP ( $\left.p=0.037\right), \mathrm{L} 2 / 3$ PV versus L5 pyramidal (RS) $(p=0.0030), \mathrm{L} 2 / 3$ PV versus L5 SOM ( $\left.p=0.0014\right), \mathrm{L} 2 / 3$ PV versus L2/3 VIP $(0.0018)$ (Kruskal-Wallis test, Bonferroni correction for multiple comparisons).

cell to cell (coefficient of variation of duration among cells $=1.46, n=$ 104 cells), but minimally within a recording of a given cell (mean coefficient of variation of duration within a cell $=0.24, n=104$ cells). Up state duration was also similar across cell types in different layers, although layer 2/3 PV cells had significantly shorter Up states than several other cell groups (Table 1). However, these differences were not due to any particular membrane potential characteristics of these cells because analysis of Up state durations in paired recordings of layer 2/3 PV cells and pyramidal cells did not reveal any significant differences in Up state duration (data not shown). The time-normalized firing rates for all Up states ( $\sim 10 \mathrm{Up}$ states) in a recording from a given cell were then averaged to give a mean time-dependent firing rate for that cell. The mean timedependent firing rates of all cells of a certain type were averaged to give the mean time-dependent firing rates for each cell type (see Fig. 6B). Time-dependent SDs of membrane potential during Up states were computed with a running SD on voltage traces. Voltage traces were first truncated at $-40 \mathrm{mV}$ to remove spikes and interpolated in regions that contained spikes. A moving average $(M A)$ with a window of $50 \mathrm{~ms}$ was computed on voltage trace $V(t)$ and on the square of voltage trace $V(t)$. The running $\mathrm{SD}(R S D)$ was then computed as follows:

$$
R S D(V(t))=\sqrt{M A\left(V(t)^{2}\right)-\left(M A(V(t))^{2}\right.}
$$

Similar to time-dependent firing rate, the time-dependent SD was normalized in time so that $t$ runs from 0 to 1 . The time-normalized SDs for all Up states ( $\sim 10 \mathrm{Up}$ states) in a recording from a given cell were then averaged to give a mean time-dependent SD for that cell. The mean time-dependent SDs of all cells of a certain type were averaged to give the mean time-dependent SDs for each cell type (see Fig. $7 B$ ).

To construct cross-correlograms of membrane potential between interneurons and pyramidal cells, cross-correlations were calculated on voltage traces from paired recordings of these cells. Voltage traces were first truncated at $-40 \mathrm{mV}$ to remove spikes and interpolated in regions that contained spikes. To avoid cross-correlations due to Up-state onset and termination, the first and last $70 \mathrm{~ms}$ of the voltage traces were removed. The voltage trace from the pyramidal cell was used as a reference trace, and correlations between this trace and the voltage trace from the interneuron were computed at time lags of $5 \mathrm{~ms}$ increment. Raw crosscorrelograms were constructed for $\sim 10 \mathrm{Up}$ states in a given paired recording. To construct shuffled cross-correlograms, cross-correlations were calculated between Up states in the pyramidal cell and randomly selected Up states in the interneuron (without replacement). The $\sim 10$ raw and shuffled cross-correlograms for each paired recording were averaged to give a mean raw and shuffled cross-correlogram for a given pair. The mean cross-correlograms for all paired recordings with an interneuron subtype were then averaged to give the mean crosscorrelogram for that interneuron subtype (see Fig. $8 B$ ). To test whether pyramidal-interneuron pairs were monosynaptically connected, 10 sweeps of $20 \mathrm{~Hz}$ trains of current pulses were injected into the putative presynaptic cell while monitoring voltage (in current clamp) or current (in voltage clamp) deflections of the putative postsynaptic cell.

Excitatory and inhibitory conductances during Up states were solved using the method of Wehr and Zador (2003). For voltage-clamp recordings, recorded currents during Up states at each holding potential (generally $-60,-10$, and $30 \mathrm{mV}$ ) were first subtracted from baseline current values ( $\sim 100 \mathrm{~ms}$ before the Up state) and then normalized by their duration, such that the duration of each Up state was $0-1$. These timenormalized current traces of Up states (usually $\sim 10$ ) were then averaged for each holding potential. Recorded voltages for each Up state were similarly normalized and averaged. We did not use an independent reference signal (e.g., a cell recorded in current-clamp or an extracellular field recording) for determination of Up state onset or termination during voltage-clamp recordings. However, the differences in Up state onset/termination at different holding potentials were likely to be negligible because paired recordings of pyramidal cells held at $-60 \mathrm{mV}$ (both cells), or at $-10 \mathrm{mV}$ (both), or at $-60 \mathrm{mV}$ and $-10 \mathrm{mV}$, did not reveal systematic differences in Up state onset/termination times. Thus, differences in Up state onset/termination times between cells held at different potentials were not significantly different from those of cells held at the same potential (data not shown). For determination of total synaptic, excitatory, and inhibitory synaptic conductance during the Up state, the following steps were taken.

1. The total synaptic current for each holding potential was calculated by:

$$
I_{s y n}(t)=I_{r e c}(t)-\frac{V_{r e c}(t)}{R_{i n}},
$$

where $I_{s y n}$ is the total synaptic current, $I_{r e c}$ is the recorded current (normalized and averaged), $V_{r e c}$ is the recorded voltage (normalized and averaged), and $R_{\text {in }}$ is the input resistance of the cell.

2. Because $I_{s y n}$ for each holding potential has the same duration, timedependent current-voltage plots could be constructed by plotting $I_{s y n}$ and $V_{\text {rec }}$ for each holding potential and for each time point, from 0 to 1. For each time point, a line was fitted to the plot of $I_{s y n}$ versus $V_{\text {rec }}$, the slope and $x$-intercept of which is the synaptic conductance $\left(g_{s y n}\right)$, and synaptic reversal potential $\left(E_{s y n}\right)$, respectively, at this time point.

3. With $g_{s y n}(t)$ and $E_{s y n}(t)$ determined, excitatory and inhibitory conductances $\left(g_{e}\right.$ and $\left.g_{i}\right)$ could be solved separately. Using the fact that:

$$
g_{\text {syn }}(t)=g_{e}(t)+g_{i}(t)
$$

and

$$
E_{s y n}(t)=\frac{I_{s y n}(t)}{g_{s y n}(t)}=\frac{g_{e}(t) E_{e}+g_{i}(t) E_{i}}{g_{e}(t)+g_{i}(t)},
$$

$g_{e}(t)$ and $g_{i}(t)$ could be solved separately:

$$
g_{e}(t)=g_{s y n}(t)\left(\frac{E_{s y n}(t)-E_{i}}{E_{e}-E_{i}}\right), g_{i}(t)=g_{s y n}(t)\left(\frac{E_{s y n}(t)-E_{e}}{E_{i}-E_{e}}\right)
$$

$E_{e}$ and $E_{i}$ were determined experimentally by recording from cells with Cs-gluconate internal solution and modified ACSF as the external solution. To determine $E_{e}, 50 \mu \mathrm{M}$ picrotoxin was bath-applied to completely block $\mathrm{GABA}_{\mathrm{A}}$ responses, and $50 \mu \mathrm{M} \mathrm{APV}$ and $10 \mu \mathrm{M}$ DNQX were bathapplied to completely block NMDA responses and only partially block AMPA responses, respectively, to avoid paroxysmal activity. The cell was held at various potentials in voltage clamp while stimulating nearby with a twisted bipolar electrode. The potential at which the synaptic responses of the cell reversed were considered the reversal potential for excitation. To determine $E_{i}, 50 \mu \mathrm{M}$ APV and DNQX were bath-applied while similarly stimulating and recording in voltage clamp. The experimentally determined reversal potentials, uncorrected for the liquid junction potential, were $E_{e}=$ $7.1 \pm 2.0 \mathrm{mV}(n=7$ cells $)$ and $E_{i}=-53.9 \pm 1.9 \mathrm{mV}(n=7$ cells $)$. 
PV immunohistochemistry in SOM-tdTomato mice. SOM-tdTomato mice aged P20 were used for all immunohistochemical work. Tissue was sectioned in either the thalamocortical plane for barrel cortex or in the horizontal plane for entorhinal cortex, as described above. All slices were incubated for $1 \mathrm{~h}$ in ACSF and then fixed by transfer to $4 \%$ PFA for $24 \mathrm{~h}$. Slices were changed to $30 \%$ sucrose, $0.1 \mathrm{M}$ phosphate buffer until resectioned at $40 \mu \mathrm{m}$. Tissue was washed twice in 0.1 sodium phosphate $(\mathrm{PB})$ followed by 3 washes in $\mathrm{PB}$ with $0.15 \mathrm{M} \mathrm{NaCl}$, $\mathrm{pH} 7.4$ (PBS). Sections were incubated in blocking solution ( $0.1 \%$ Tween, $0.25 \%$, Triton $\mathrm{X}-100,10 \%$ normal goat serum in PBS) for $1 \mathrm{~h}$ for nonspecific binding, then incubated in mouse monoclonal anti-parvalbumin antibody (Swant, clone 235, 1:2000) for $2.7 \mathrm{~d}$ with rotation at $4^{\circ} \mathrm{C}$. Following primary incubation, tissue was rinsed 5 times at $5 \mathrm{~min}$ each rinse in PBS and then preblocked for 45 min in blocking solution as above. Tissue was incubated in Alexa-488 goat anti-mouse IgG at 1:500 (Invitrogen, A11001) for $2 \mathrm{~h}$ at room temperature, rinsed three times in PBS, $10 \mathrm{~min}$ each, followed by two rinses of PB. All sections were mounted from $0.01 \mathrm{M} \mathrm{PB}$ and coverslipped using Vectashield (Vector, H-1000). Photomicrographs of immunostained slices were taken using a SPOT Camera (Spot Software, version 4.7, Diagnostic Instruments) mounted to a Nikon microscope (Nikon Eclipse, E600).

Somatostatin and VIP immunohistochemistry in NPY-GFP mice. NPY-GFP mice aged P20 were used. Tissue was prepared as described above in the thalamocortical plane for visualization of the barrel cortex. Immunohistochemistry was performed as above using somatostatin (rabbit-anti-somatostatin-14 polyclonal, Bachem, \#T4103 at 1:1000) and VIP antibodies (rabbit-anti-VIP, ImmunoStar, \#20077 at 1:1000), each run separately in sister sections. Following primary incubation for $2.7 \mathrm{~d}$ with rotation at $4^{\circ} \mathrm{C}$, tissue was rinsed and blocked as above, then incubated in Alexa-568 goat anti-rabbit IgG at 1:500 (Invitrogen, A11036) for $2 \mathrm{~h}$ at room temperature. The procedure then proceeded as described above.

Statistics. For statistical comparisons, distributions of data were first tested for normality with a Kolmogorov-Smirnov test. If data were normally distributed, standard parametric statistics were used: unpaired or paired $t$ tests for comparisons of two groups and one-way or repeatedmeasures ANOVA for comparisons of multiple groups. If data were not normally distributed, nonparametric statistics were used: Mann-Whitney or Wilcoxon's matched pairs test for comparisons of two groups and Kruskal-Wallis or Friedman's test for comparisons of multiple groups. Bonferroni correction was used for multiple comparisons. $p$ values $<0.05$ were considered significant. All analyses of data were conducted in Mathematica 8 (Wolfram Research). Error bars and error shadings are SEM, unless otherwise noted.

\section{Results}

We have characterized the firing properties, subthreshold dynamics, and synaptic conductances of excitatory and inhibitory cells during Up states in layers 5 and 2/3 of mouse barrel cortex. These two layers have distinct roles in recurrent cortical activity. Whereas Up states are requisitely initiated in layer 5 (SanchezVives and McCormick, 2000; Beltramo et al., 2013), feedforward projections from layer $2 / 3$ to layer 5 enhance recurrent network activity and contribute to its propagation (Wester and Contreras, 2012). We studied excitatory pyramidal cells and four subtypes of inhibitory interneurons: PV-, SOM-, VIP-, and NPY-positive cells (Fig. 1). Interneurons were identified for recording by Credriven expression of tdTomato or endogenous expression of GFP (see Materials and Methods). Expression of PV, SOM, VIP, and NPY is largely nonoverlapping and accounts for nearly all GABAergic cells in somatosensory cortex (Lee et al., 2010). Whereas PV cells and SOM cells are located in both layers 5 and $2 / 3$, VIP and NPY cells are primarily localized to layer $2 / 3$. To ensure that GFP in the NPY-GFP animal did not label a substantial number of other interneuron subtypes in layer $2 / 3$, we performed SOM and VIP immunohistochemistry in slices of barrel cortex from the NPY-GFP animal (see Materials and Methods). We found that in layer $2 / 3, \sim 6 \%$ (14 of 253) of GFP-positive cells also expressed SOM and $~ 8 \%$ (55 of 711) also expressed VIP. Notably, the overlap of SOM and GFP expression was higher in layers 5 and 6 ( 94 of $236 \approx 40 \%$ ), but we did not target NPY-GFP cells for recording in these layers. Thus, SOM and VIP immunohistochemistry suggests that there is an $\sim 6 \%$ chance of off-targeting a SOM cell and an $\sim 8 \%$ chance of off-targeting a VIP cell by using fluorescence to target layer $2 / 3$ cells in the NPY-GFP mouse.

\section{Intrinsic properties of pyramidal cells and interneurons}

The intrinsic physiological properties of the cells are summarized in Table 2. Most of the pyramidal cells in both layers 5 and $2 / 3$ had a regular spiking (RS) phenotype, characterized by spikefrequency adaptation and progressively growing afterhyperpolarizations during a spike train (Fig. 2). Some $(n=3)$ of the layer 5 pyramidal cells exhibited bursts of action potentials with suprathreshold current injection (Fig. 2), which we classified as intrinsically bursting (IB) cells (Connors et al., 1982; ChagnacAmitai et al., 1990; Kasper et al., 1994; Hefti and Smith, 2000; Sun et al., 2013). All of the recorded PV cells in both layers 5 and $2 / 3$ 
Table 2. Properties of excitatory and inhibitory neurons in barrel cortex ${ }^{a}$

\begin{tabular}{|c|c|c|c|c|c|c|c|c|c|}
\hline & $\begin{array}{l}\text { L5 Pyr (RS) } \\
(n=44)\end{array}$ & $\begin{array}{l}5 \text { Pyr (IB) } \\
(n=3)\end{array}$ & $\begin{array}{l}\text { L2/3 Pyr } \\
(n=88)\end{array}$ & $\begin{array}{l}\text { L5 PV } \\
(n=43)\end{array}$ & $\begin{array}{l}\mathrm{L} 2 / 3 \mathrm{PV} \\
(n=34)\end{array}$ & $\begin{array}{l}\text { L5 SOM } \\
(n=45)\end{array}$ & $\begin{array}{l}\mathrm{L} 2 / 3 \mathrm{SOM} \\
(n=50)\end{array}$ & $\begin{array}{l}\text { L2/3 VIP } \\
(n=37)\end{array}$ & $\begin{array}{l}\text { L2/3 NPY } \\
(n=23)\end{array}$ \\
\hline $\mathrm{RMP}(\mathrm{mV})$ & $-63.5(3.2)$ & $-59.0(1.7)$ & $-67.4(4.3)$ & $-67.1(3.2)$ & $-66.4(3.0)$ & $-63.2(4.0)$ & $-59.9(4.0)$ & $-65.7(1.9)$ & $-66.4(3.6)$ \\
\hline $\mathrm{R}_{\mathrm{in}}(\mathrm{M} \Omega)$ & $48.0(25.9)$ & $27.1(13.3)$ & $45.7(19.6)$ & $49.4(33.0)$ & $33.0(7.6)$ & $79.7(41.0)$ & $95.7(53.0)$ & $126.0(54.7)$ & $89.8(31.2)$ \\
\hline AP thresh (mV) & $-44.8(5.3)$ & $-50.5(0.5)$ & $-41.5(6.0)$ & $-42.3(5.0)$ & $-41.6(3.4)$ & $-48.1(8.0)$ & $-41.8(6.3)$ & $-43.7(5.3)$ & $-38.7(5.6)$ \\
\hline$\tau_{\mathrm{m}}(\mathrm{ms})$ & $11.8(4.8)$ & $16.6(6.6)$ & $10.5(5.1)$ & $4.0(1.8)$ & $3.1(1.3)$ & $11.7(7.5)$ & $11.8(4.6)$ & $10.9(3.8)$ & $10.0(8.8)$ \\
\hline AP half-width (ms) & $0.66(1.1)$ & $0.58(0.5)$ & $0.84(0.3)$ & $0.25(0.05)$ & $0.22(0.04)$ & $0.40(0.05)$ & $0.44(0.1)$ & $0.45(0.1)$ & $0.66(0.4)$ \\
\hline Up firing rate $(\mathrm{Hz})$ & $4.9(4.2)$ & $15.8(2.9)$ & $1.7(2.6)$ & $30.6(1.4)$ & $26.5(19.5)$ & $9.7(9.0)$ & $8.0(13.1)$ & $5.9(8.6)$ & $1.6(2.0)$ \\
\hline Up depolarization (mV) & $4.4(1.6)$ & $2.6(1.7)$ & $6.8(2.6)$ & $8.5(3.2)$ & $8.3(2.5)$ & $3.9(2.7)$ & $3.2(1.7)$ & $5.1(2.4)$ & $6.2(0.8)$ \\
\hline$\sigma_{\text {Up }} / \sigma_{\text {Down }}$ & $10.7(5.3)$ & $13.7(8.8)$ & $11.7(7.7)$ & $10.4(4.1)$ & $17.5(4.7)$ & $6.4(4.9)$ & $5.9(4.0)$ & $6.4(2.9)$ & $6.5(2.1)$ \\
\hline$G_{E}(n S)$ & $1.5(2.0)$ & $N A^{*}$ & $2.8(1.6)$ & $2.7(1.9)$ & $4.9(2.8)$ & $2.1(1.8)$ & $1.5(1.26)$ & $1.0(0.4)$ & $0.9(0.5)$ \\
\hline$G_{i}(n S)$ & $3.4(1.6)$ & $N A^{*}$ & $4.7(3.1)$ & $1.0(1.4)$ & $1.3(0.8)$ & $1.1(1.4)$ & $1.0(0.8)$ & $1.2(0.7)$ & $1.8(1.6)$ \\
\hline
\end{tabular}

${ }^{a}$ Values are mean (SD). RMP, Resting membrane potential; $\mathrm{R}_{\text {in }}$, input resistance; AP thresh, action potential threshold; $\tau_{\mathrm{m}}$, membrane time constant; AP half-width, action potential half-width; $\sigma_{U \mathrm{u}} / \sigma_{\mathrm{Down}}$, normalized membrane potential $S D$ during Up state; $G_{E}$, excitatory conductance; $G_{1}$, inhibitory conductance. $n$ refers to the total number of cells studied in current clamp and voltage clamp.

*NA, Not applicable; RS cells could not be distinguished from IB cells using Cs-gluconate internal solution.

exhibited a FS phenotype, with little spike-frequency adaptation and brief action potential widths (Fig. 2; Table 2). Most recorded SOM cells exhibited spike-frequency adaptation and a so-called low-threshold spiking (LTS) phenotype; spike and afterhyperpolarization amplitudes decreased toward steady-state values during a train (Beierlein et al., 2003) (Fig. 2). SOM cells also had relatively high input resistances and depolarized resting membrane potentials (Table 2). Although there was some variability in the spiking behavior of VIP cells to suprathreshold current injection, many of these cells exhibited substantial spike-frequency adaption (Fig. 2). VIP cells also had the highest input resistances of all the cell types studied (Table 2). Most NPY cells exhibited spike-frequency adaption and responded with a delayed spike with near-threshold current injection (Fig. 2), typical of neurogliaform cells in somatosensory (Simon et al., 2005), frontal (Kawaguchi and Kubota, 1997), and entorhinal cortex (Tahvildari et al., 2012).

\section{Spontaneous and evoked Up states}

Cortical slices can generate spontaneous, rhythmic recurrent activity when superfused with ACSF containing a lower-thantraditional concentration of divalent cations and a higher concentration of potassium (Sanchez-Vives and McCormick, 2000). The exact periodicity and duration of Up states in cortical slices may depend upon the precise divergence and convergence of intracortical connectivity, and cortical area, species, and age (Fanselow and Connors, 2010; Sanchez-Vives, 2012).

An important factor for the promotion of network activity in slices is the delivery of oxygenated solution. Several forms of network activity in hippocampal slices are enhanced when the flow rate of ACSF is high, which increases oxygen levels in the slice (Hájos et al., 2009). Oxygenation is presumably critical for the occurrence of cortical Up states in vitro as well. Thus, we used the maximal flow rate of our perfusion system $(\sim 10 \mathrm{ml} / \mathrm{min})$ while superfusing the slice from above and below (see Materials and Methods). With this modification, we were reliably able to record Up states in barrel cortex slices from mice aged up to P19 (Fig. $3 A, B$ ). We did not observe an appreciable decrease in either Up state duration or Up state frequency with animal age (Fig. $3 C, D$ ), in contrast to previous observations in barrel cortex slices using more traditional superfusion conditions (Fanselow and Connors, 2010). Slices from older animals may be more susceptible to insufficient oxygen delivery to cells due to diffusion barriers contributed by myelination or age-dependent metabolic changes (Maruoka et al., 2001), and thus might require modifications, such as ours, to study network activity.
In addition to recording spontaneous Up states, we were also able to evoke Up states by electrically stimulating cortical layer 5 (see Materials and Methods). Consistent with previous reports (Shu et al., 2003b), low-intensity electrical stimulation of layer 5 resulted in Up states that were very similar to spontaneous Up states (Fig. 3E). Except for a small but significant difference in the mean amplitude of excitatory synaptic currents, the properties of spontaneous and evoked Up states were indistinguishable (Fig. $3 F)$. Thus, spontaneous and evoked Up states were combined in our analysis.

\section{Firing rates of pyramidal cells and interneurons during Up states}

As a measure of the differential activation of cell types during Up states, we first considered their firing rates. All cell types tended to spike during Up states (Figs. 4, 5, and 6A), and firing rates decreased as the Up state progressed (Fig. 6B). There were, however, several differences among particular cell types in the magnitudes of their firing rate. FS PV cells were by far the most active cell type, firing action potentials at an average of $30.6 \mathrm{~Hz}$ in layer 5 and 26.5 $\mathrm{Hz}$ in layer $2 / 3$ (Figs. 5 and $6 A$ ). This suggests that PV cells contribute most of the inhibitory modulation of the Up state. Other interneuron subtypes, however, were not silent, in contrast to previous recordings in entorhinal cortex (Tahvildari et al., 2012). Rather, in both layers 5 and 2/3, SOM, VIP, and NPY cells were as active or more active than neighboring pyramidal cells (Figs. 5 and 6). Consistent with previous work (Fanselow and Connors, 2010), a fraction of SOM cells $(36 \%, n=25$ in layer $5 ; 22 \%, n=$ 32 in layer 2/3), in addition to one of the IB pyramidal cells, fired action potentials during the Down state as well (Figs. 4 and 5). Layer 5 and 2/3 SOM cells that fired during the Down state fired at a rate of $4.8 \pm 1.3 \mathrm{~Hz}$ and $5.6 \pm 1.3 \mathrm{~Hz}$, respectively, whereas the one IB pyramidal cell in layer 5 fired at a rate of $4.3 \mathrm{~Hz}$ (Fig. 4).

Pyramidal cells in layer 5 fired significantly more than pyramidal cells in layer $2 / 3\left(4.9 \mathrm{~Hz}\right.$ vs $\left.1.7 \mathrm{~Hz}, p=8 \times 10^{-5}\right)$ (Figs. 4 and $6 A$ ). This difference may be due, in part, to differences in resting membrane potential and spike threshold between these two groups of pyramidal cells (Table 2); layer 5 pyramidal cells had a more depolarized resting membrane potential than layer $2 / 3$ pyramidal cells $\left(-63.5\right.$ vs $\left.-67.4 \mathrm{mV}, p=7 \times 10^{-5}\right)$ and more hyperpolarized spike threshold $(-44.8 \mathrm{vs}-41.5 \mathrm{mV}, p=$ 0.009 ). Indeed, layer $2 / 3$ pyramidal cells were more depolarized than layer 5 pyramidal cells during Up states $(6.8 \mathrm{mV}$ vs $4.4 \mathrm{mV}$, $\left.p=1.1 \times 10^{-5}\right)$, suggesting that insufficient synaptic drive to layer $2 / 3$ cells does not explain their low firing rates (see below). Furthermore, whereas only 2 of 31 pyramidal cells in layer 5 fired 

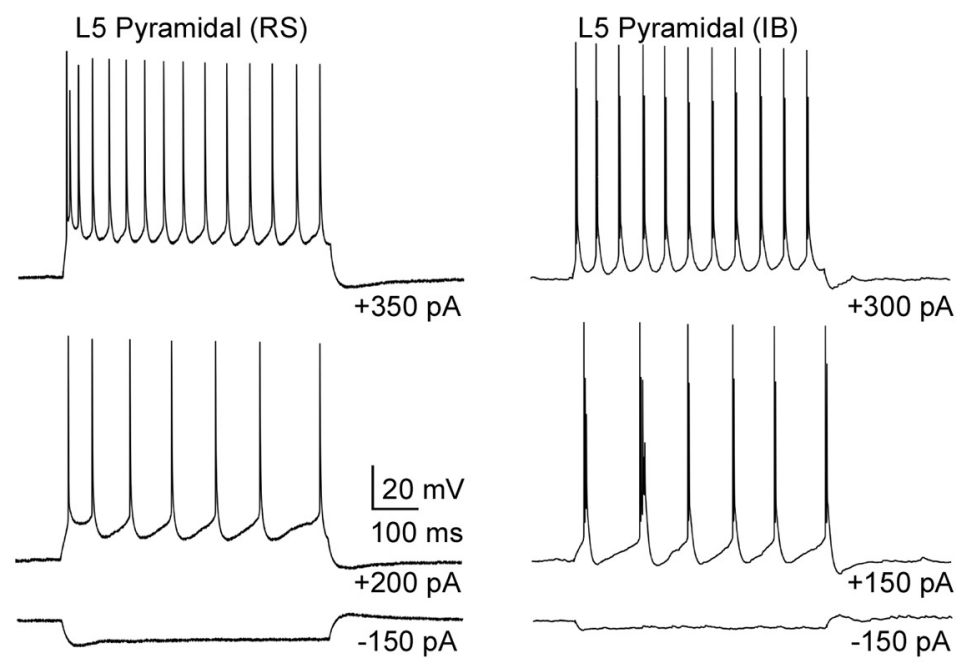

L5 PV

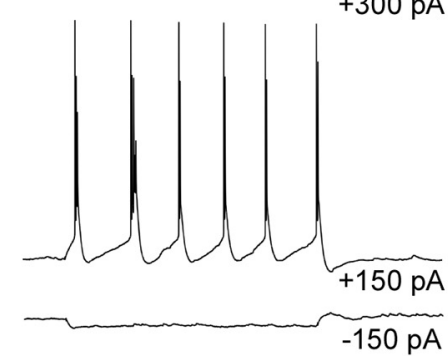

$+700 \mathrm{pA}$

L5 SOM

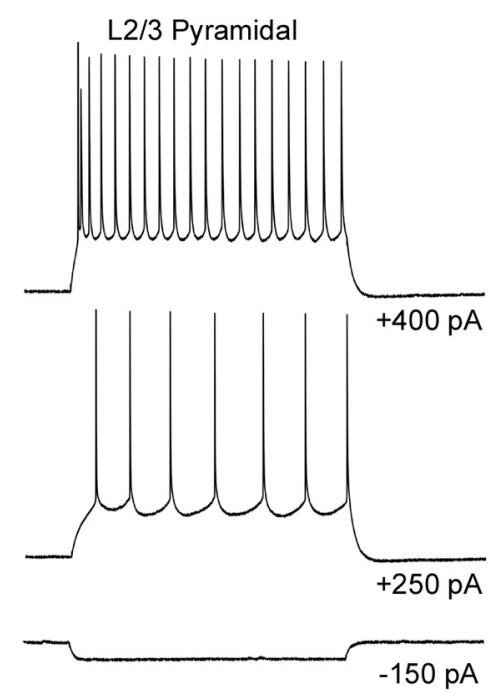

L2/3 PV
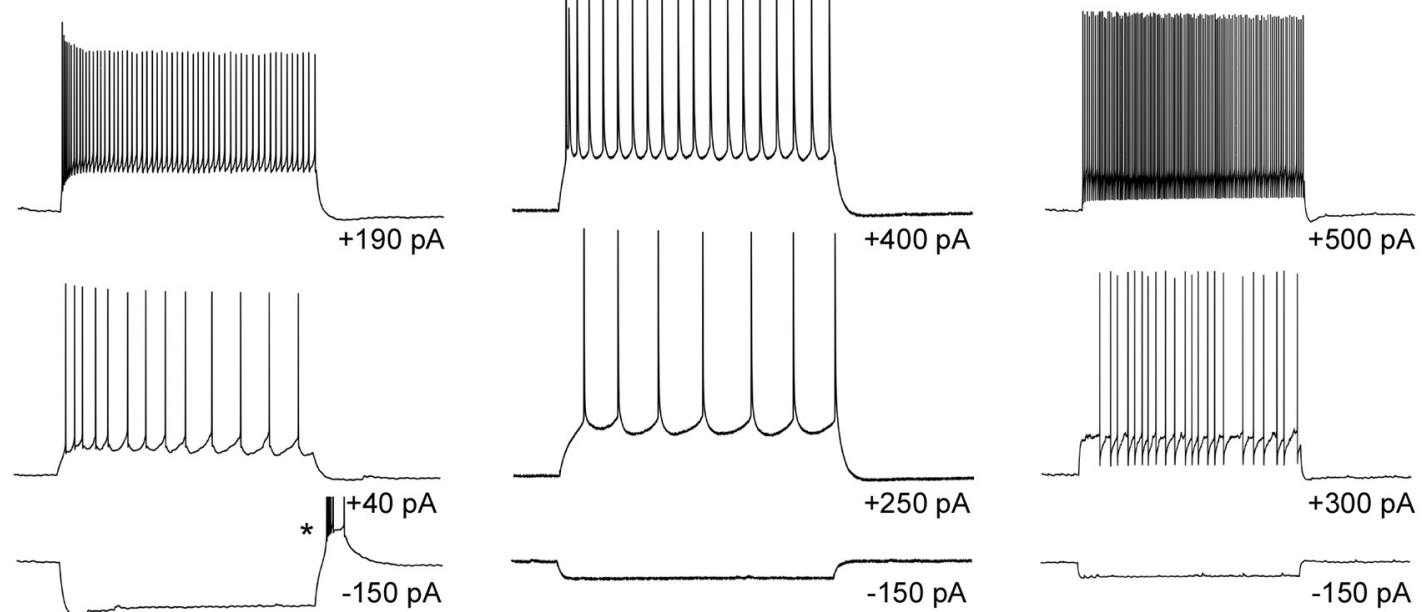

L2/3 SOM

L2/3 VIP
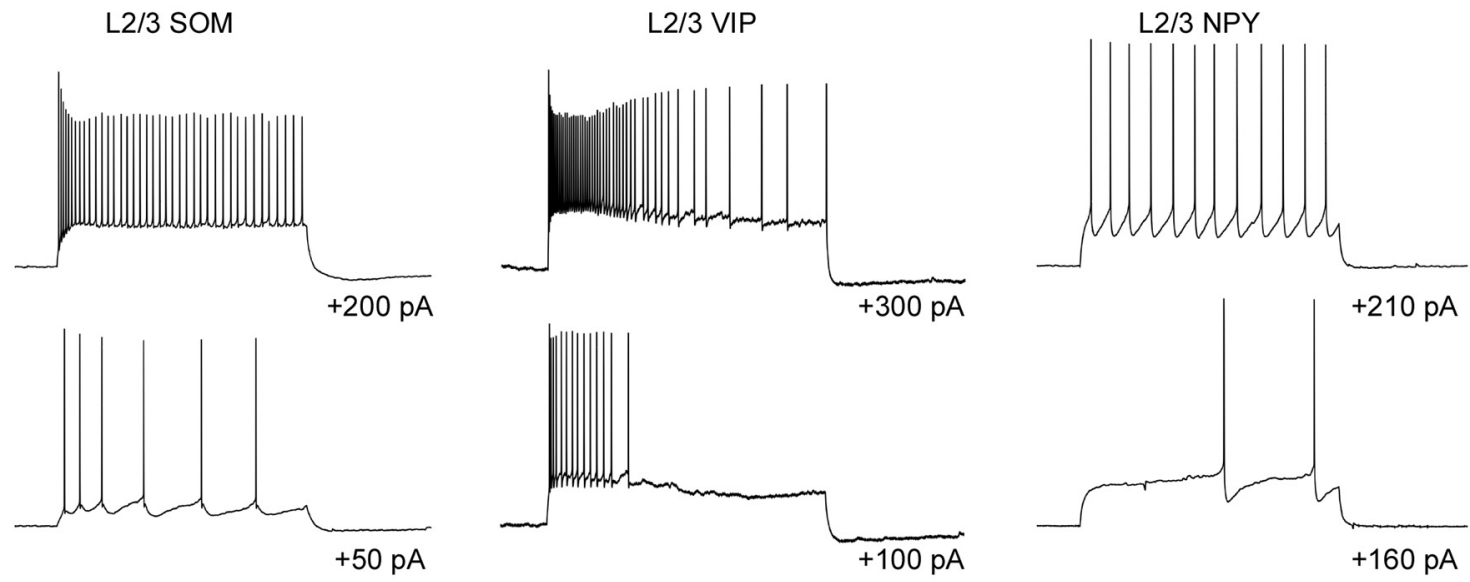

$-150 \mathrm{pA}$
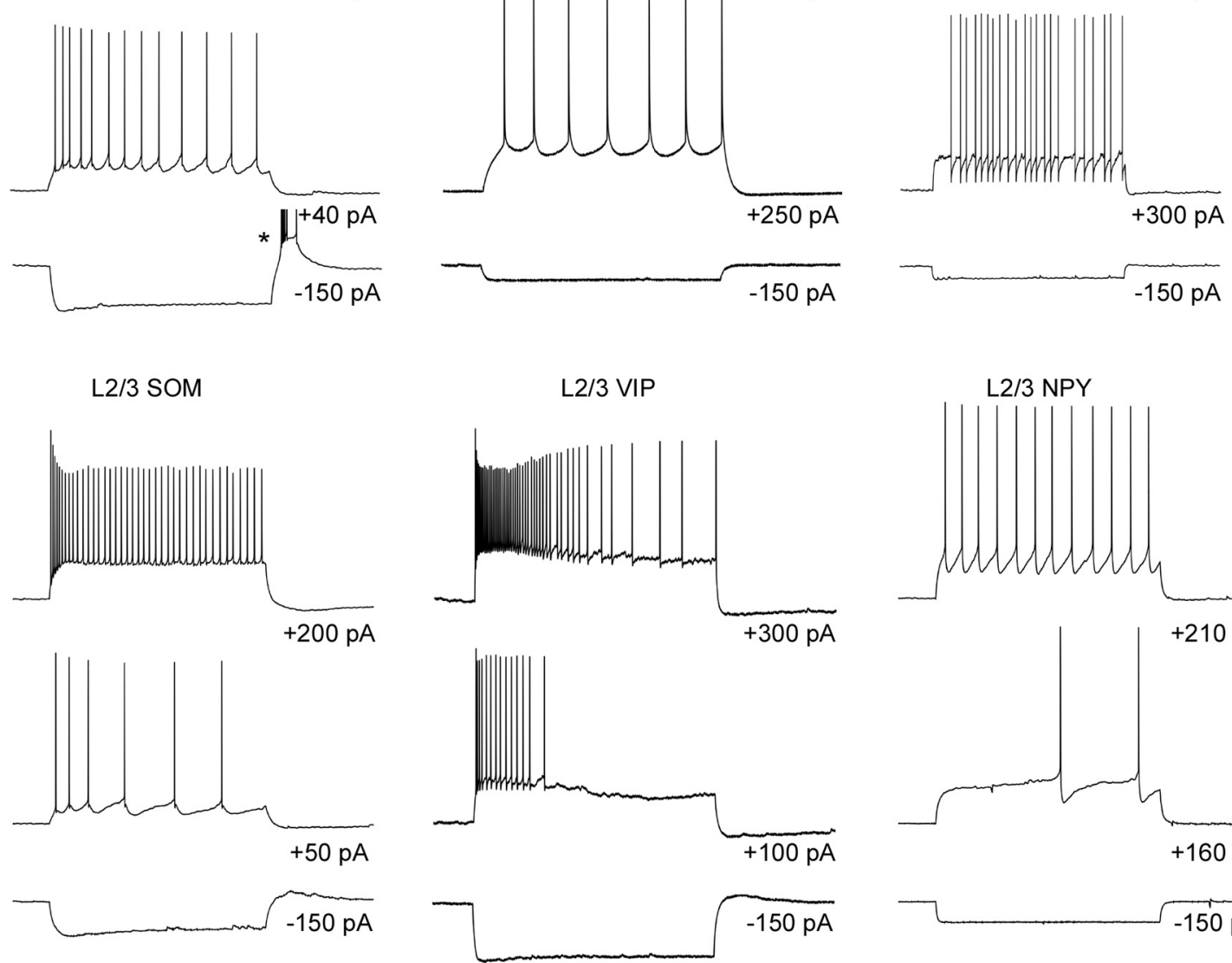

Figure 2. Intrinsic properties of pyramidal cells and interneurons in barrel cortex. Representative voltage traces represent responses to hyperpolarizing and two levels of depolarizing suprathreshold current pulses. Spikes in the rebound burst in the L5 SOM cell are truncated (indicated by an asterisk). 

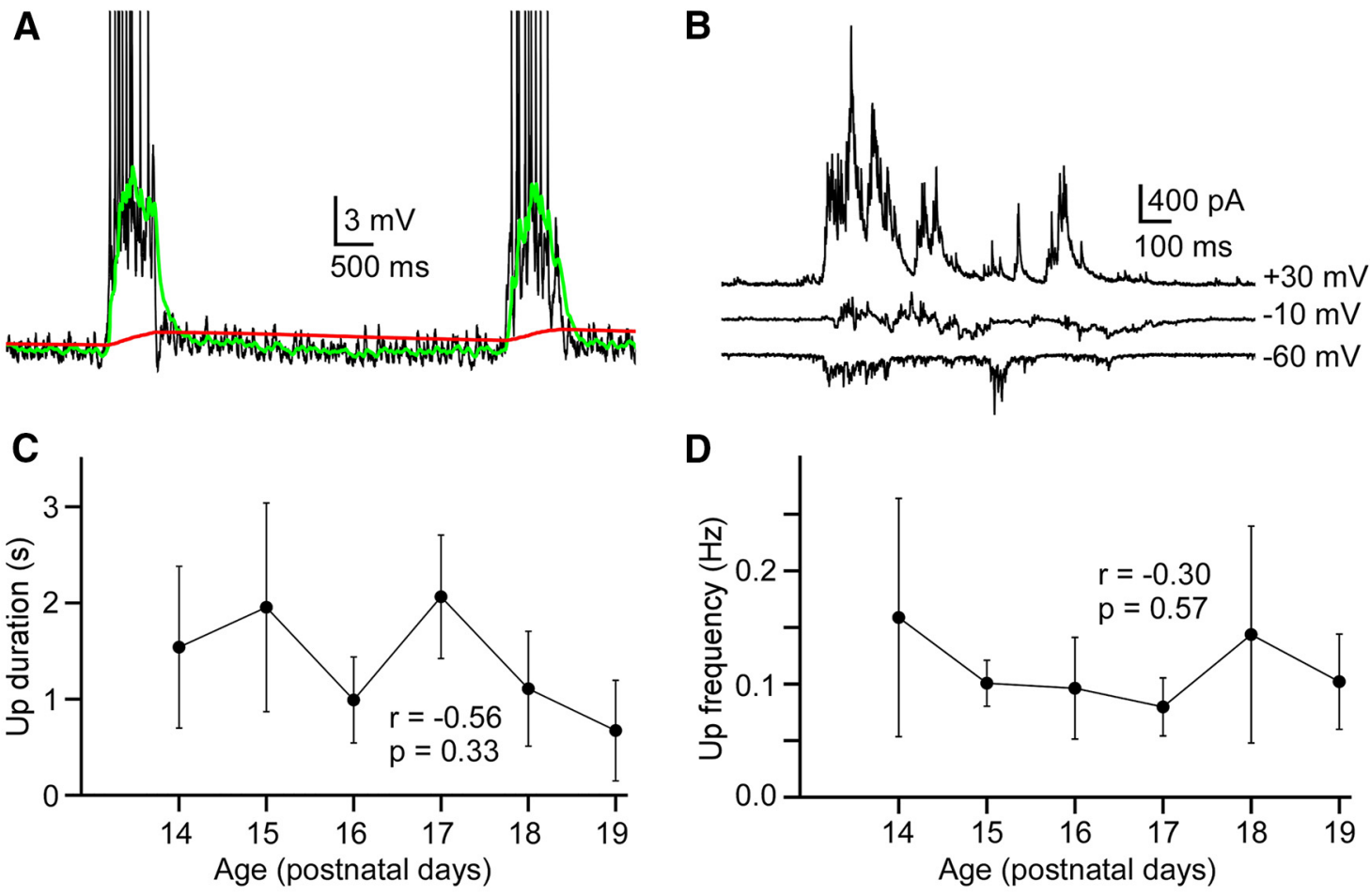

E

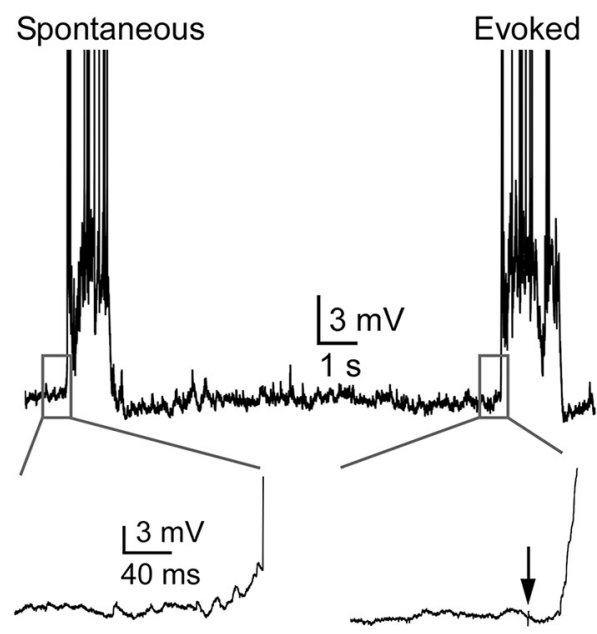

$\mathbf{F}$
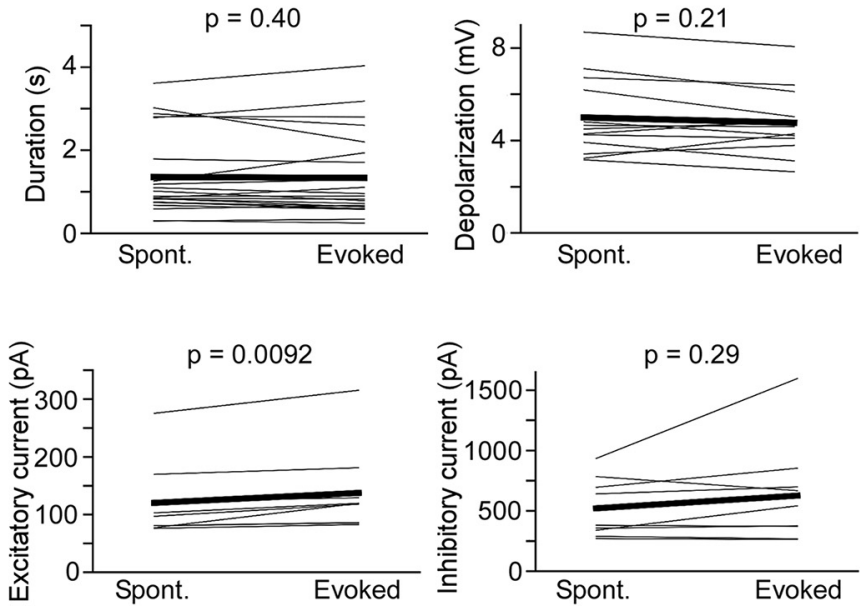

Figure 3. Properties of spontaneous and evoked Up states. A, Implementation of the offline algorithm for detecting Up and Down state transitions in a L5 pyramidal cell. Green trace represents a "fast" exponential moving average. Red trace represents a "slow" exponential moving average. The points of intersection of these two traces are considered the Up state initiation and termination times. Action potentials are truncated. $\boldsymbol{B}$, Up states recorded in voltage clamp at different holding potentials from an $L 5$ pyramidal cell. C, Up state duration was not correlated with age $(n=20, P 14$; $n=20, \mathrm{P} 15 ; n=18, \mathrm{P} 16 ; n=7, \mathrm{P} 17 ; n=15, \mathrm{P} 18 ; n=13, \mathrm{P} 19)$. Error bars indicate SD. D, Up state frequency was not correlated with age $(n=10, \mathrm{P} 14 ; n=9, \mathrm{P} 15 ; n=9, \mathrm{P} 16 ; n=8, \mathrm{P} 17 ; n=$ $8, P 18 ; n=10, P 19)$. Error bars indicate SD. E, Examples of spontaneous and electrically evoked Up states recorded in the same $L 5$ pyramidal cell. Insets, Magnification of traces near the Up state onset. Action potentials are truncated. $F$, Comparisons of spontaneous and electrically evoked Up states in $L 5$ and $L 2 / 3$ pyramidal cells. Data from single cells are paired. The only significant difference between spontaneous and evoked Up states was in the excitatory current ( $n=22$, duration; $n=13$, depolarization; $n=13$, firing rate; $n=9$ excitatory current; $n=9$, inhibitory current).

no action potentials during the Up state, a substantial fraction $(40 \%, n=73)$ of pyramidal cells in layer $2 / 3$ fired no action potentials during the Up state.

Differences in intrinsic properties, such as resting membrane potential, input resistance, or spike threshold, did not seem to account for the subpopulation-related differences in firing during the Up and Down states. Layer 2/3 pyramidal cells that fired during the Up state did not significantly differ in resting membrane potential, input resistance, or spike threshold from layer $2 / 3$ pyramidal cells that did not fire during the Up state (data not shown). SOM cells that fired during the Down state also did not differ significantly from SOM cells that did not fire during the Down state, with the exception of spike threshold in layer 5 SOM cells (Down-state-firing: $-52.9 \mathrm{mV}$, Down-state-silent: -45.6 $\mathrm{mV}, p=0.038)$. The total lack of firing of $40 \%$ of layer $2 / 3$ pyramidal cells may be due to an excess of synaptic inhibition in these cells (see below), whereas the firing of a certain population of SOM cells during the Down state may be due to differential expression of intrinsic currents (Le Bon-Jego and Yuste, 2007). In general, there was no significant relationship between Up state firing rate and intrinsic cellular properties for excitatory and inhibitory cells: only a few weak, but significant, correlations be- 
L5 pyramidal (RS)

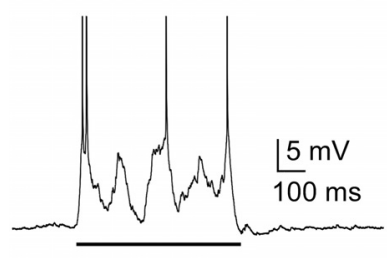

L5 pyramidal (IB)
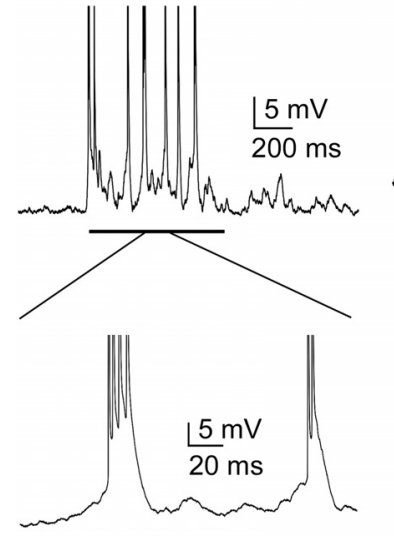

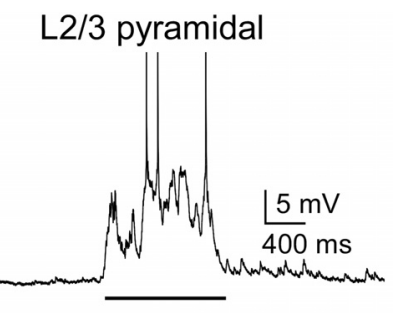

L5 pyramidal (IB)
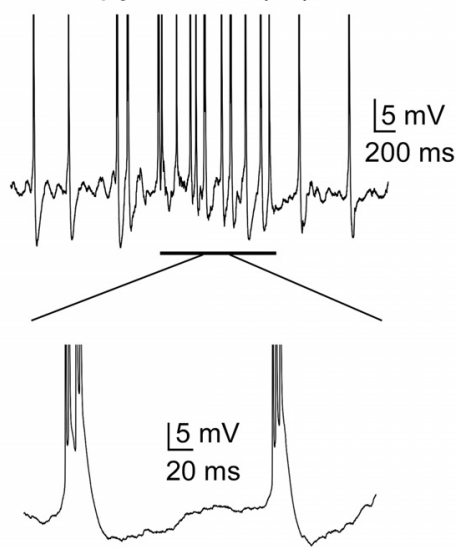

Figure 4. Properties of Up states in pyramidal cells. Representative voltage traces show the subthreshold and spiking responses of pyramidal cells in layers 5 and 2/3. Two different IB cells are shown: one did not spike during the Down state, and the other did spike during the Down state. Solid black line underneath traces indicates Up states. RS, Regular spiking; IB, intrinsic bursting. Action potentials are truncated to show subthreshold behavior. Insets under IB traces, Spiking behavior during Up states.

tween firing rate and some of the intrinsic excitability measures (firing rate vs RMP: L5 SOM, $r=-0.51, p=0.016$; firing rate vs $\mathrm{R}_{\text {in }}$ : L5 Pyr, $r=-0.40, p=0.038$; firing rate vs AP thresh: L5 Pyr, $r=-0.532, p=0.0043$ and L2/3 Pyr, $r=-0.29, p=0.020)$.

We conclude that FS PV cells have the highest firing rate of all cell types studied during Up states, but that the other interneuron subtypes (SOM, VIP, and NPY) are as active or more active than neighboring excitatory pyramidal cells.

\section{Membrane potential dynamics and correlations during Up states}

During Up states, the membrane potential of cortical neurons fluctuates due to barrages of excitatory and inhibitory synaptic inputs. Membrane potential fluctuations increase the probability of spiking to small inputs and control the input-output characteristics of neurons (Shu et al., 2003a). We calculated a running SD of the subthreshold potentials of excitatory and inhibitory neurons during Up states, normalized by the SD of the membrane potential during the Down state $\left(\sigma_{\mathrm{Up}} / \sigma_{\text {Down }}\right)$ (see Materials and Methods). The mean $\sigma_{\mathrm{Up}} / \sigma_{\text {Down }}$ reached at least 5 for all neuron types and did not change substantially with the progression of the Up state after an initial peak at the onset of the Up state (Fig. 7B). PV cells had the highest mean $\sigma_{\mathrm{Up}} / \sigma_{\text {Down }}$ of all cell types, although values for pyramidal cells were also high. SOM, VIP, and NPY cells exhibited similar, lower membrane potential fluctuations.

We estimated the level of shared synaptic drive to neighboring neurons by calculating cross-correlations of membrane potential fluctuations obtained from paired recordings of pyramidal cells and PV, SOM, VIP, or NPY cells in the same cortical layer. Although cross-correlations of isolated synaptic currents between
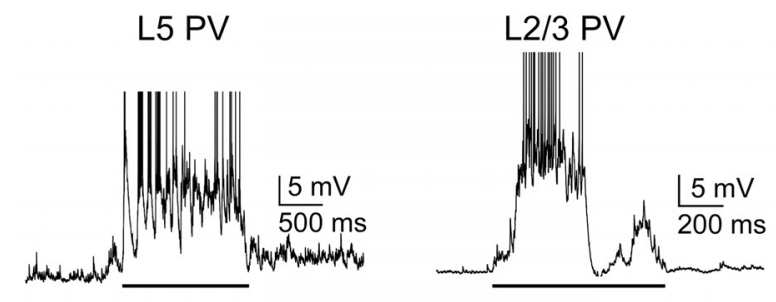

L5 SOM

L5 SOM
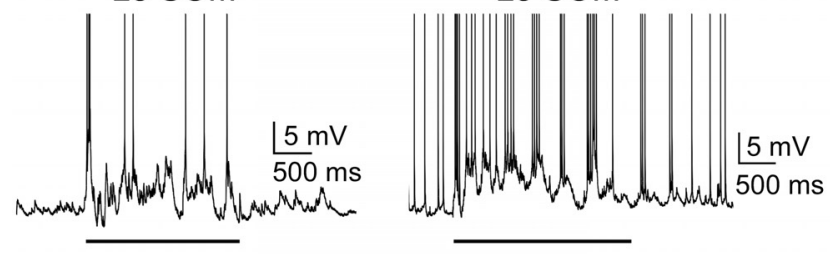

L2/3 SOM
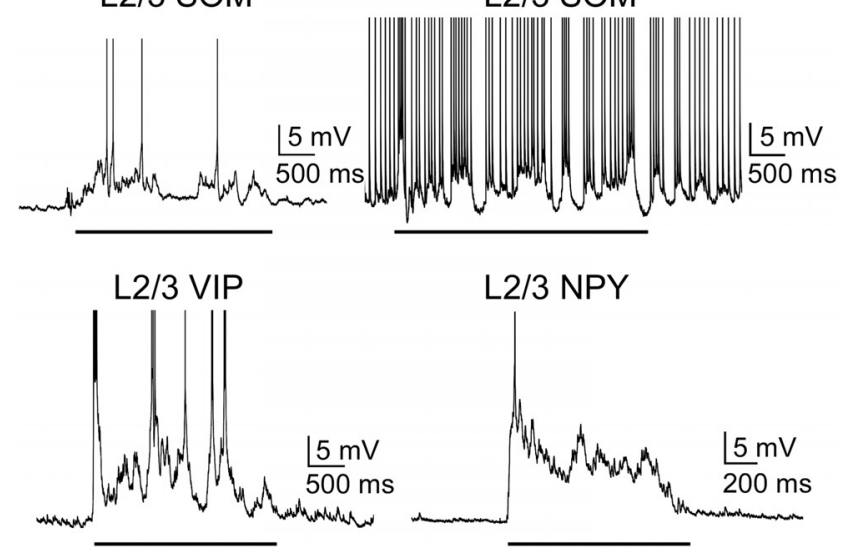

L2/3 NPY

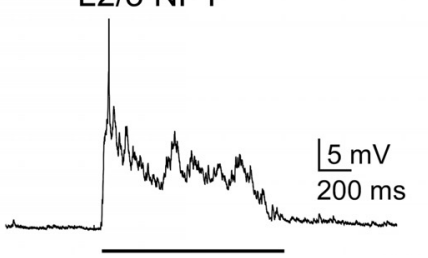

Figure 5. Properties of Up states in interneurons. Representative voltage traces show the subthreshold and spiking responses of PV and SOM cells in layers 5 and $2 / 3$ and VIP and NPY cells in layer 2/3. For the L5 and L2/3 SOM cells, two different SOM cells are shown: one did not spike during the Down state, and one did spike during the Down state. Solid black line indicates Up states. Action potentials are truncated to show subthreshold behavior.

cells provide the most direct measure of shared synaptic inputs, cross-correlations of membrane potential fluctuations often reflect the level of correlated synaptic drive as well (Poulet and Petersen, 2008; Yu and Ferster, 2010). Pyramidal cells and interneurons were generally separated by less than the width of a single barrel (mean center-to-center distances: layer 5 pyramidalPV: $106 \pm 10 \mu \mathrm{m}$; layer $2 / 3$ pyramidal-PV: $104 \pm 12 \mu \mathrm{m}$; layer 5 pyramidal-SOM: $91 \pm 12 \mu \mathrm{m}$; layer $2 / 3$ pyramidal-SOM: $97 \pm 9$ $\mu \mathrm{m}$; layer $2 / 3$ pyramidal-VIP: $71 \pm 10 \mu \mathrm{m}$; layer $2 / 3$ pyramidal-NPY: $89 \pm 13 \mu \mathrm{m}$ ). Most of the pairs did not exhibit monosynaptic connections (data not shown), suggesting that the cross-correlograms reflect shared synaptic drive from the entire local cortical network and are not dominated by interactions between recorded pairs. All cross-correlograms exhibited a peak at or near zero-lag (Fig. 8B). Although pyramidal-VIP and pyramidal-NPY pairs had the highest peak cross-correlations, the only significant difference was between pyramidal-SOM pairs in layer $2 / 3$ (the lowest peak cross-correlation in the dataset) and pyramidal-NPY pairs (the highest peak cross-correlation in the dataset) (Fig. 8A).

Overall, the membrane potential fluctuations of pyramidal cells and all types of neighboring interneurons during Up states were correlated, suggesting that different interneuron subtypes receive roughly similar amounts of shared synaptic drive during Up states. 
A

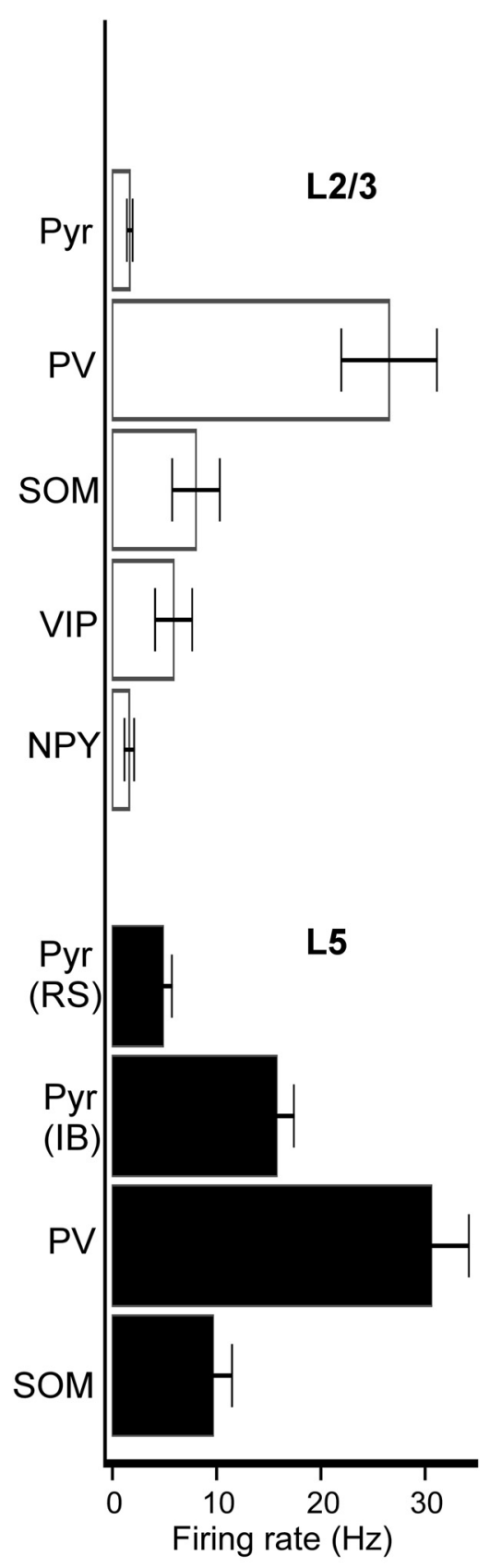

B
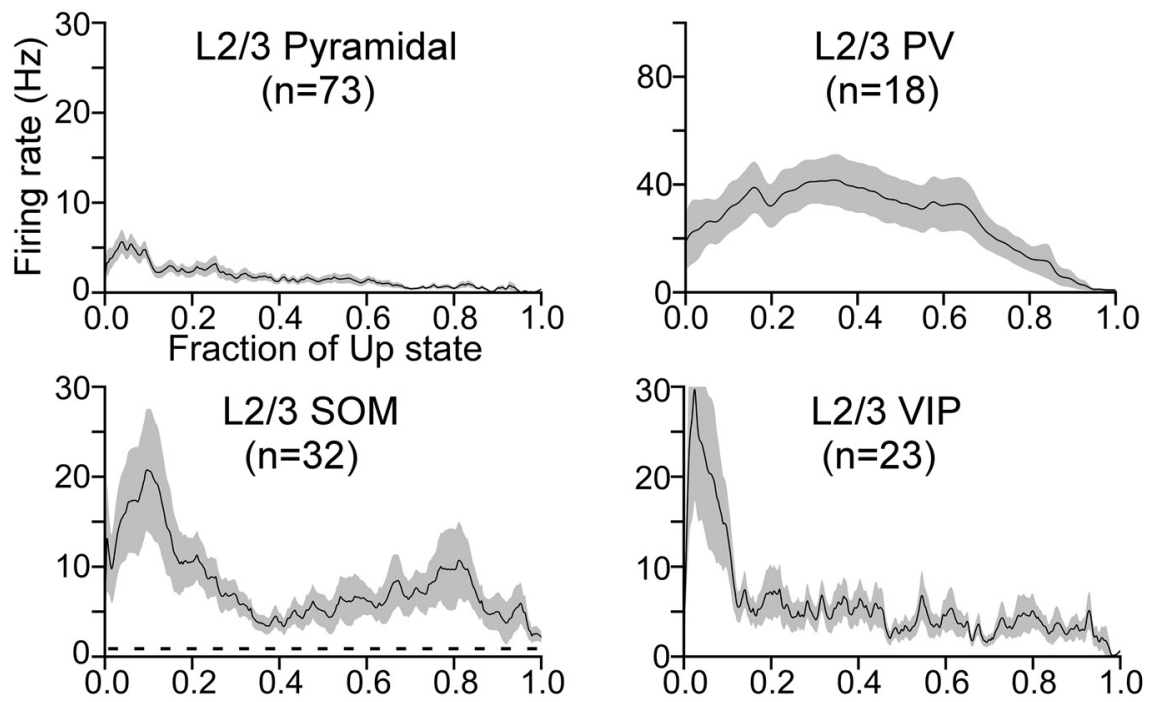
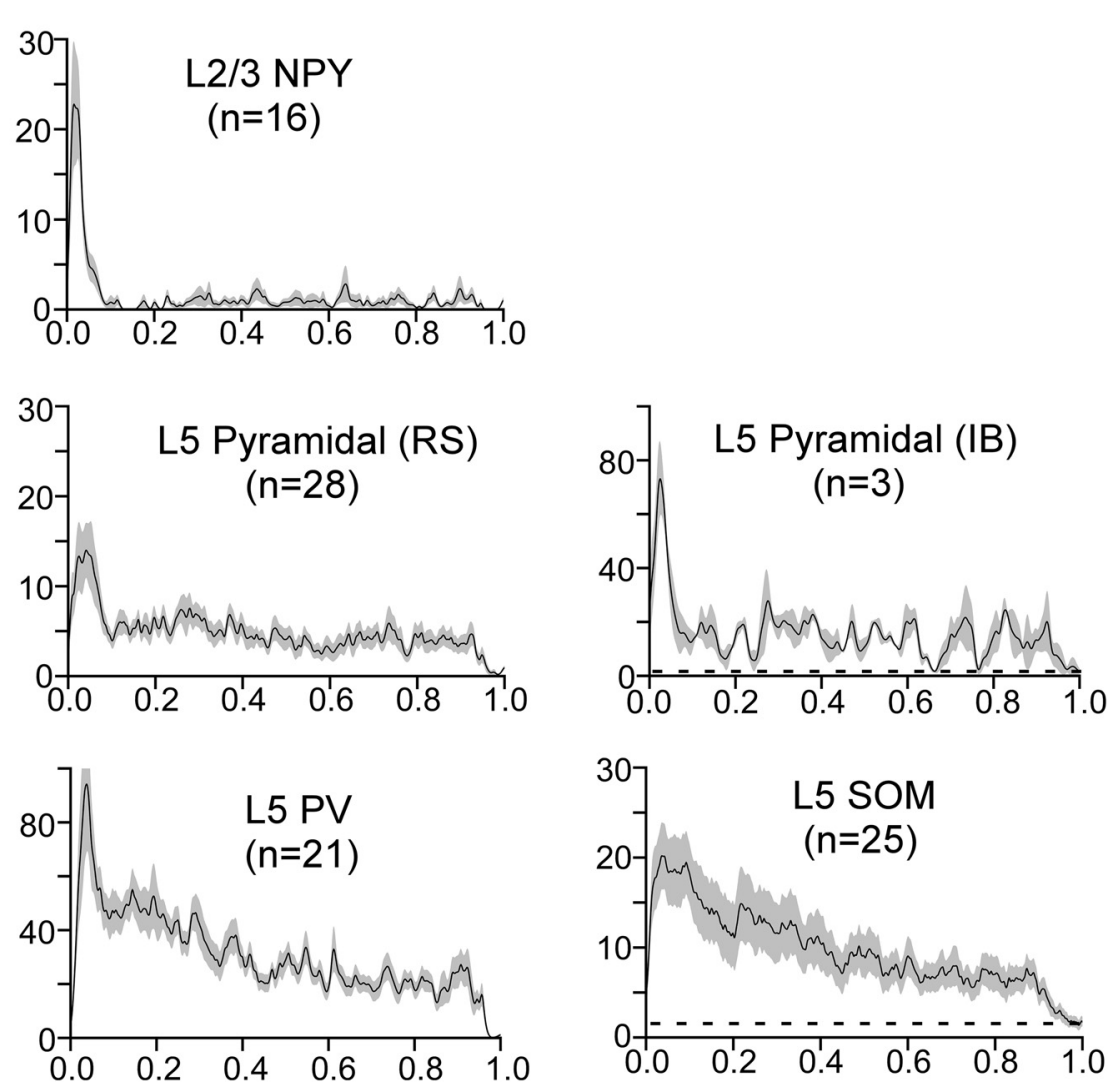

Figure 6. Firing rates of pyramidal cells and interneurons during Up states $\boldsymbol{A}$, Mean total firing rates of pyramidal cells and interneurons. Error bars indicate SEM. $\boldsymbol{B}$, Mean time-dependent firing rates of pyramidal cells and interneurons. Firing rates are plotted as a function of the fraction of the Up state (i.e., the time axis is normalized from 0 to 1 to average across recordings with different Up-state durations). Dashed lines underneath waveforms for SOM cells and L5 IB pyramidal cells indicate mean Down state firing rates (Down state firing rates for all other cell types are zero). Note the different firing-rate axis for PV cells and L5 IB cells. Shading represents SEM. The following comparisons were significant (Kruskal-Wallis test, Bonferroni correction): $R_{L 5}$ Pyr, RS $>R_{L 2 / 3}$ Pyr $(p=$ $\left.7.6 \times 10^{-5}\right), \mathrm{R}_{\mathrm{L} 5 \mathrm{Pyr}, \mathrm{RS}}<\mathrm{R}_{\mathrm{LS} \mathrm{PV}}\left(p=8.8 \times 10^{-11}\right), \mathrm{R}_{\mathrm{L} 5 \mathrm{Pyr}, \mathrm{RS}}<\mathrm{R}_{\mathrm{L} 2 / 3 \mathrm{PV}}\left(p=2.3 \times 10^{-4}\right), \mathrm{R}_{\mathrm{L} 5 \mathrm{Pyr}, \mathrm{RS}}>\mathrm{R}_{\mathrm{L} 2 / 3 \mathrm{NPY}}(p=0.032), \mathrm{R}_{\mathrm{L} 2 / 3 \mathrm{Pyr}}<\mathrm{R}_{\mathrm{L} 5 \mathrm{PV}}\left(p=2.5 \times 10^{-15}\right), \mathrm{R}_{\mathrm{L} 2 / 3 \mathrm{Pyr}}<\mathrm{R}_{\mathrm{LL} / 3 \mathrm{PV}}(p=8.5$

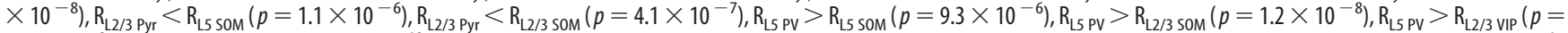

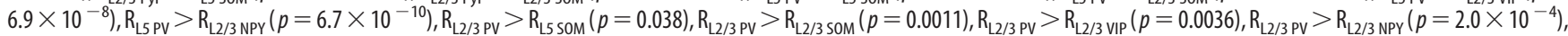
$R_{L 5 \text { SOM }}>R_{L 2 / 3 \mathrm{NPY}}(p=0.0019), R_{\mathrm{LL} / 3 \text { SOM }}>R_{\mathrm{L} 2 / 3 \mathrm{NPY}}(p=0.0060)$.

Excitatory and inhibitory synaptic conductances during Up states

During Up states, cortical neurons receive barrages of excitatory and inhibitory synaptic inputs, which reflect the firing of pyramidal cells and interneurons. We performed voltage clamp record- ings of cells at a range of holding potentials to estimate excitatory and inhibitory conductances during Up states (see Materials and Methods). Pyramidal cells and PV cells had the largest mean synaptic conductances during the Up state (Fig. 9A). Interestingly, in all cell types, the inhibitory conductance peaked early in 
A

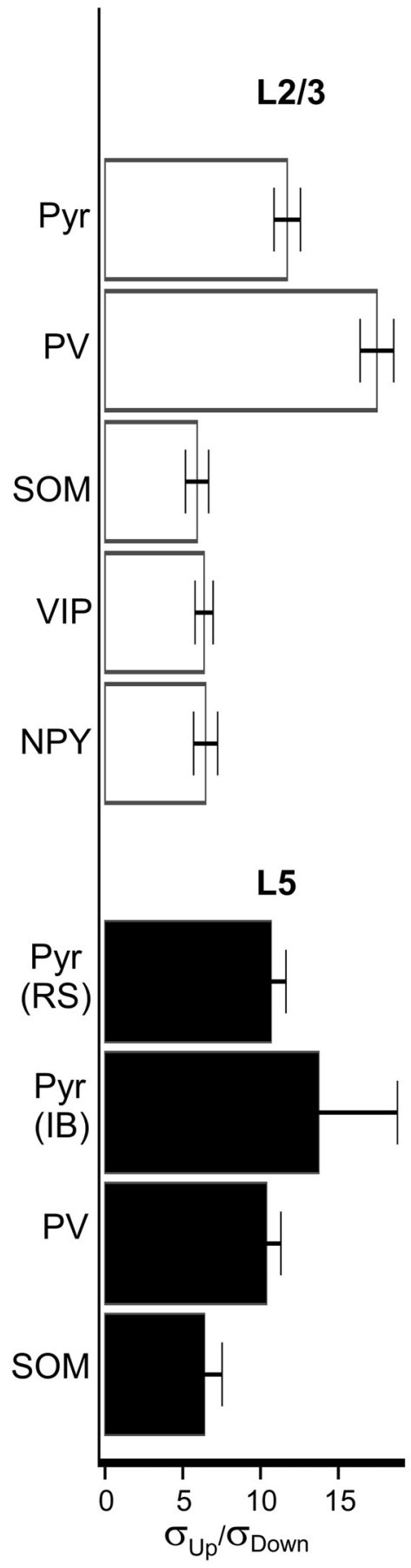

B
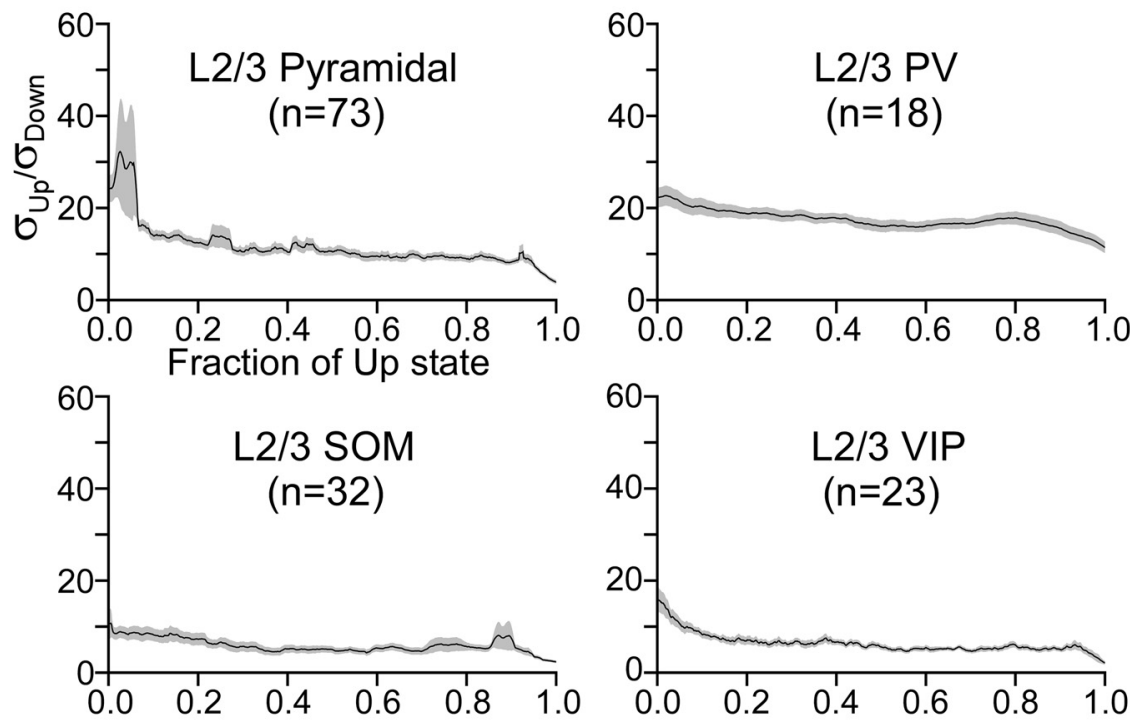
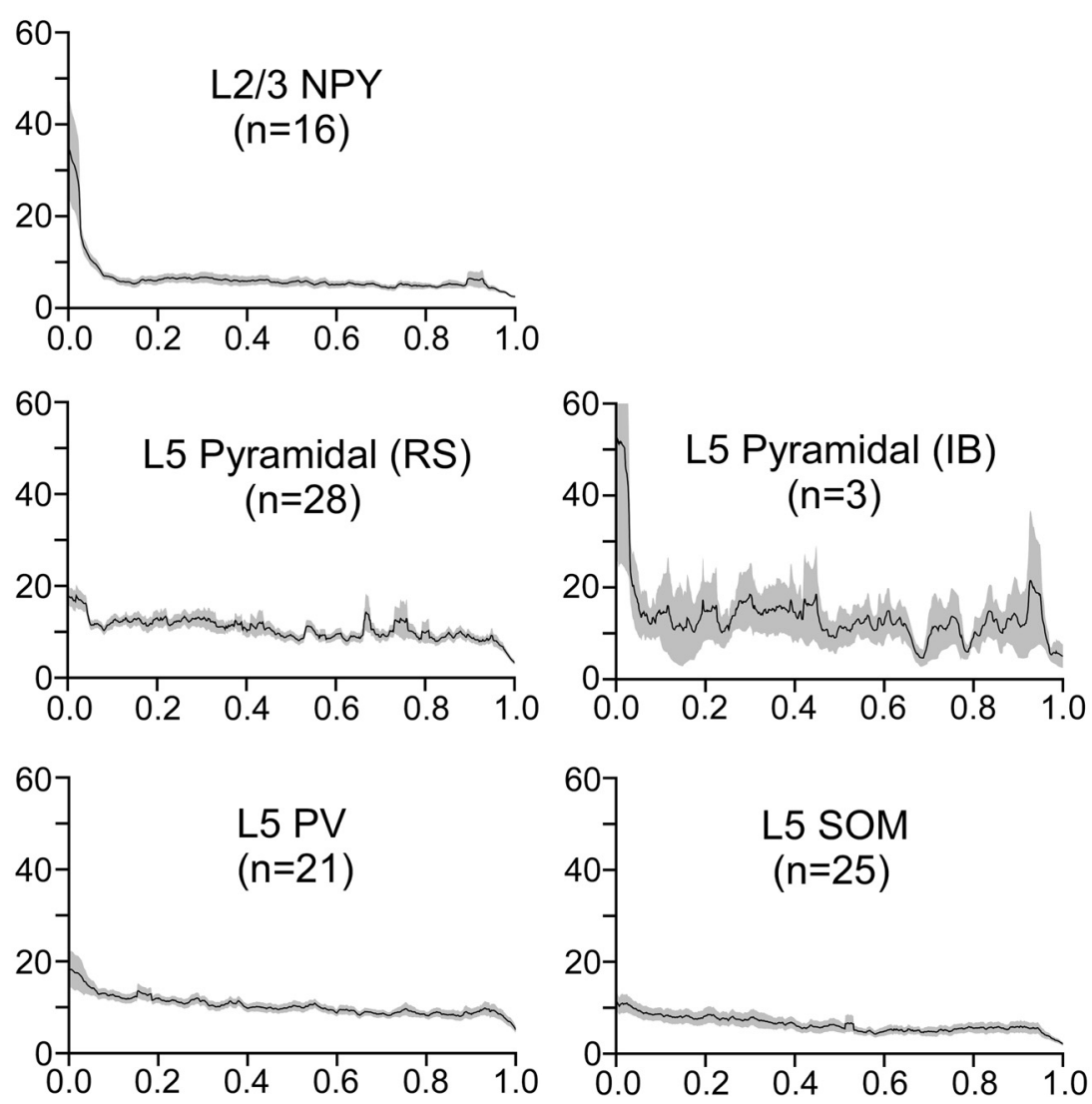

Figure 7. Membrane potential dynamics of pyramidal cells and interneurons during Up states. $A$, Mean total membrane potential SDs of pyramidal cells and interneurons. Up-state membrane potential SDs are expressed as multiples of Down-state membrane potential SDs (e.g., a value of $\sigma_{\mathrm{Up}} / \sigma_{\text {Down }}=5$ indicates that the membrane potential SD was 5 times higher during the Up state than during the Down state). Error bars indicate SEM. B, Mean time-dependent SDs of the membrane potential of pyramidal cells and interneurons. SDs are plotted as a function of the fraction of the Up state (i.e., the time axis is normalized from 0 to 1 to average across recordings with different Up-state durations). Shading represents SEM. The following comparisons were significant (Kruskal-Wallis test, Bonferroni correction): $\sigma_{\mathrm{L} 5 \text { Pyr RS }}<\sigma_{\mathrm{L} 2 / 3 \mathrm{PV}}(p=0.0018), \sigma_{\mathrm{L} 5 \mathrm{Pyr}, \mathrm{RS}}>\sigma_{\mathrm{LL} / 3 \mathrm{SOM}}(0.0030), \sigma_{\mathrm{L} 5 \mathrm{Pyr}, \mathrm{RS}}>\sigma_{\mathrm{L} 2 / 3 \mathrm{VIP}}(0.011), \sigma_{\mathrm{LL} / 3 \mathrm{Pyr}}>\sigma_{\mathrm{L} 2 / 3 \mathrm{PV}}\left(3.0 \times 10^{-4}\right), \sigma_{\mathrm{L} 2 / 3 \mathrm{Pyr}}>$ $\sigma_{\mathrm{L} 5 \mathrm{soM}}(0.0030), \sigma_{\mathrm{L} 2 / 3 \mathrm{Pyr}}>\sigma_{\mathrm{L} 2 / 3 \mathrm{SOM}}\left(2.9 \times 10^{-4}\right), \sigma_{\mathrm{L} 2 / 3 \mathrm{Pyr}}>\sigma_{\mathrm{LL} / 3 \mathrm{VIP}}\left(3.9 \times 10^{-5}\right), \sigma_{\mathrm{L} 2 / 3 \mathrm{Pyr}}>\sigma_{\mathrm{L} 2 / 3 \mathrm{NPY}}(0.017), \sigma_{\mathrm{L} 5 \mathrm{PV}}>\sigma_{\mathrm{L} 2 / 3 \mathrm{PV}}\left(7.3 \times 10^{-4}\right), \sigma_{\mathrm{L} 5 \mathrm{PV}}>\sigma_{\mathrm{L} 2 / 3 \mathrm{SOM}}(0.0037), \sigma_{\mathrm{L} 5 \mathrm{PV}}>$ $\sigma_{\mathrm{L} 2 / 3 \mathrm{VIP}}(0.015), \sigma_{\mathrm{LL} 2 / 3 \mathrm{PV}}>\sigma_{\mathrm{L} 5 \mathrm{SOM}}\left(2.3 \times 10^{-6}\right), \sigma_{\mathrm{L} 2 / 3 \mathrm{PV}}>\sigma_{\mathrm{L} 2 / 3 \mathrm{SOM}}\left(4.8 \times 10^{-9}\right), \sigma_{\mathrm{L} 2 / 3 \mathrm{PV}}>\sigma_{\mathrm{L} 2 / 3 \mathrm{VIP}}\left(7.0 \times 10^{-10}\right), \sigma_{\mathrm{L} 2 / 3 \mathrm{PV}}>\sigma_{\mathrm{L} 2 / 3 \mathrm{NPY}}\left(1.7 \times 10^{-8}\right)$.

the Up state (within $\sim 20 \%$ of the Up state duration), whereas in most cell types excitation reached a plateau at around the point that inhibition peaked (Fig. 9B). Another interesting feature is the dichotomy of the relative magnitude of excitation and inhibition in pyramidal cells versus PV cells. Pyramidal cells in both layers 5 and 2/3 were overwhelmingly dominated by inhibition, especially at the beginning of the Up state, although PV cells in both layers 5 and 2/3 were dominated by excitation. Other interneuron subtypes exhibited mostly balanced excitation and inhibition during the Up state; the exception was NPY cells, which exhibited signif- 


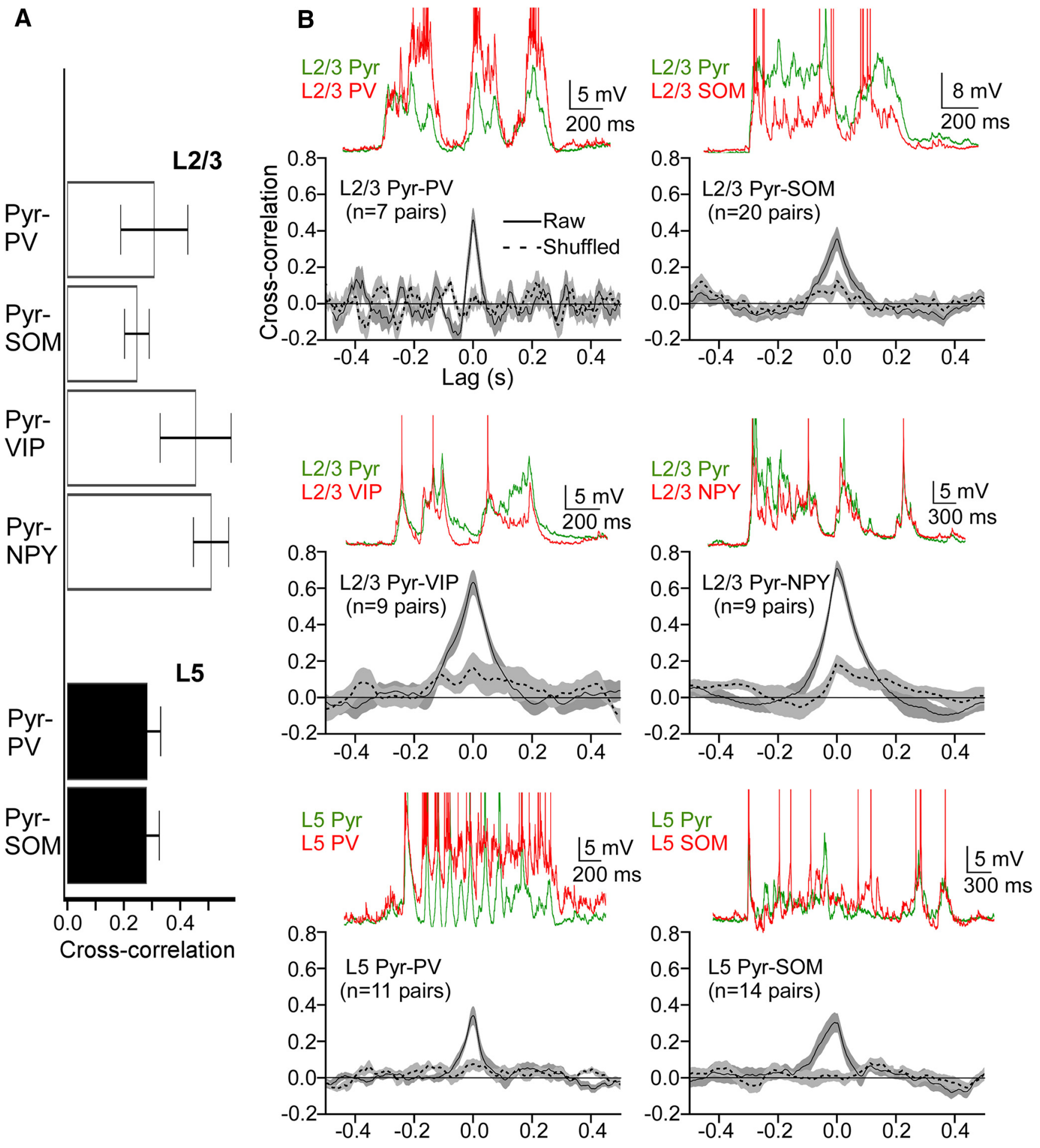

Figure 8. Membrane potential correlations between pyramidal cells and interneurons. $\boldsymbol{A}$, Mean, peak shuffle-corrected cross-correlations for pyramidal-interneuron pairs (i.e., the mean shuffled peak cross-correlation value subtracted from the mean raw peak cross-correlation value). Error bars indicate SEM. $\boldsymbol{B}$, Cross-correlograms of membrane potential fluctuations from paired recordings of pyramidal cells and interneurons. Solid black line indicates raw cross-correlations. Dashed black line indicates shuffled cross-correlations. Green and red traces above correlograms are representative voltage traces from paired recordings of the indicated pyramidal cells and interneurons. Action potentials are truncated, and traces are aligned to their baseline voltage. Shading represents SEM. The following comparisons were significant (Kruskal-Wallis test, Bonferroni correction): $\mathrm{CC}_{\mathrm{L} 2 / 3 \text { Pyr-SOM }}<\mathrm{CC}_{\mathrm{L} 2 / 3 \text { Pyr-NPY }}(p=0.047)$.

icantly larger inhibitory conductance (Fig. 9A,B). We conclude that pyramidal cells and PV cells receive the strongest synaptic inputs during the Up state. In all cell types, the inhibitory conductances peak early in the Up state, whereas excitatory conductances are more stable before dropping toward the end.
Differential activation of SOM and VIP cells in barrel cortex and entorhinal cortex

As a population, all of the interneuron subtypes we studied spiked during Up states and did so at frequencies at least as high as neighboring pyramidal cells. This contrasts with a recent study 
A

$\mathrm{L} 2 / 3$

B
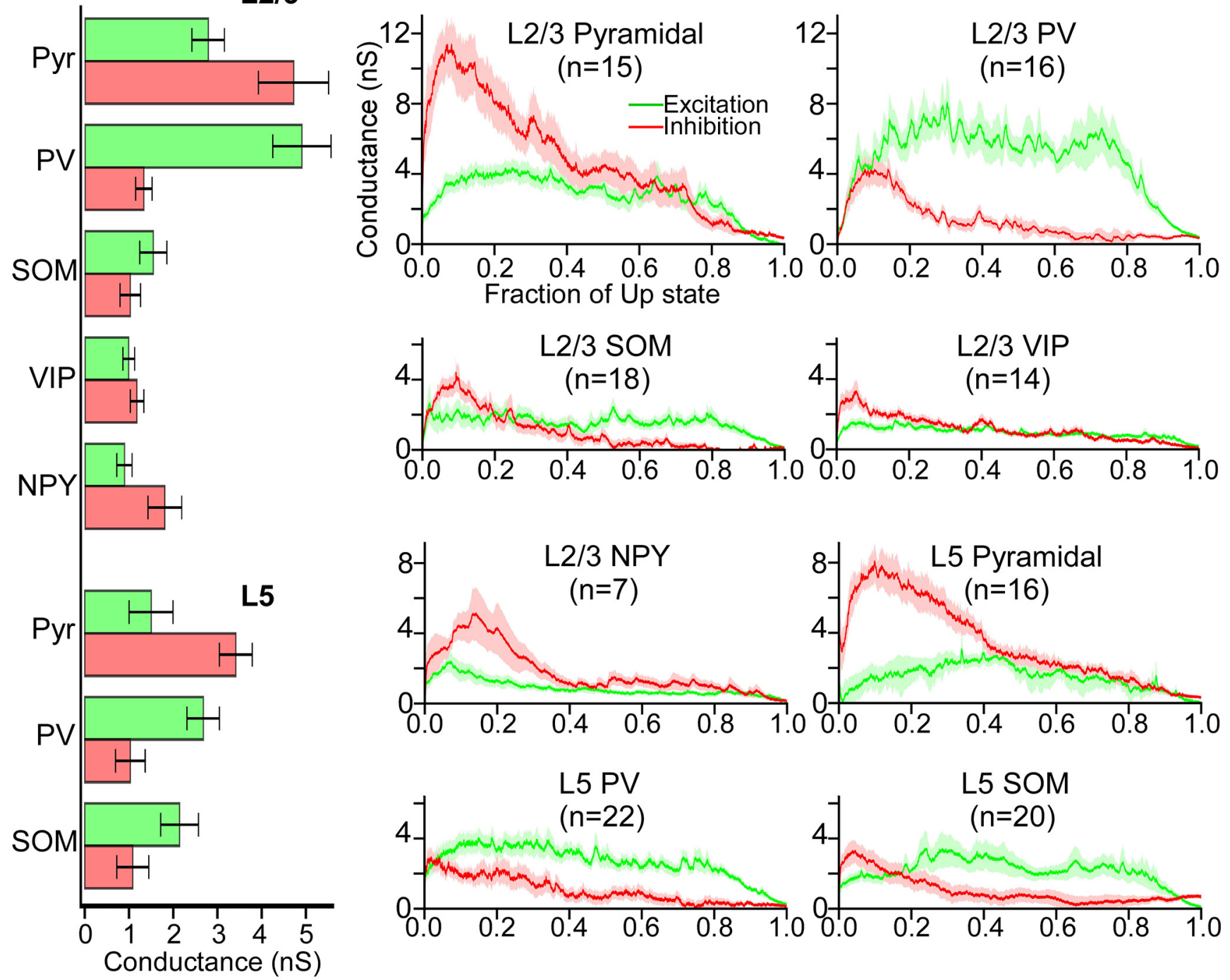

Figure 9. Excitatory and inhibitory conductances in pyramidal cells and interneurons during Up states. $A$, Mean total excitatory and inhibitory conductances of pyramidal cells and interneurons. Error bars indicate SEM. B, Mean time-dependent excitatory (green) and inhibitory (red) conductances, calculated from voltage-clamp recordings. Conductances are plotted as a function of the fraction of the Up state (i.e., the time axis is normalized from 0 to 1 to average across recordings with different Up-state durations). Shading represents SEM. The following comparisons of excitatory and inhibitory conductances within cell types were significant (Mann-Whitney test): $\mathrm{Ge}_{\mathrm{L} 5 \mathrm{Pyr}}<\mathrm{Gi}_{\mathrm{L} 5 \mathrm{Pyr}}(p=0.0019), \mathrm{Ge}_{\mathrm{L} 2 / 3 \mathrm{Pyr}}<\mathrm{Gi}_{\mathrm{L2} / 3 \mathrm{Pyr}}(p=0.036), \mathrm{Ge}_{\mathrm{LS} \text { PV }}>\mathrm{Gi}_{\mathrm{L} 5 \mathrm{PV}}(p=0.0020), \mathrm{Ge}_{\mathrm{L} 2 / 3 \mathrm{PV}}$ $>\mathrm{Gi}_{\mathrm{L} 2 / 3 \mathrm{PV}}\left(p=6.3 \times 10^{-5}\right), \mathrm{Ge}_{\mathrm{LS} \mathrm{SOM}}>\mathrm{Gi}_{\mathrm{L} 5 \text { SOM }}(p=0.0013), \mathrm{Ge}_{\mathrm{LL} / 3 \mathrm{NPY}}<\mathrm{Gi}_{\mathrm{L} 2 / 3 \mathrm{NPY}}(p=0.05)$. The following comparisons of excitatory conductances among cell types were significant (Kruskal-Wallis test, Bonferroni correction): $\mathrm{Ge}_{\mathrm{L} 5 \mathrm{Pyr}}<\mathrm{Ge}_{\mathrm{L} 2 / 3 \mathrm{PV}}\left(p=7.6 \times 10^{-4}\right), \mathrm{Ge}_{\mathrm{L} 2 / 3 \mathrm{Pyr}}>\mathrm{Ge}_{\mathrm{L} 2 / 3 \mathrm{VIP}}(p=0.017), \mathrm{Ge}_{\mathrm{L} 2 / 3} \mathrm{Pyr}>\mathrm{Ge}_{\mathrm{L} 2 / 3 \mathrm{NPY}}(p=0.039), \mathrm{Ge}_{\mathrm{L} 5 \mathrm{PV}}>\mathrm{Ge}_{\mathrm{L} 2 / 3 \mathrm{VIP}}(p=0.0020)$, $\mathrm{Ge}_{\mathrm{L} 2 / 3 \mathrm{PV}}>\mathrm{Ge}_{\mathrm{L} 5 \mathrm{SOM}}(p=0.013), \mathrm{Ge}_{\mathrm{L} 2 / 3 \mathrm{PV}}>\mathrm{Ge}_{\mathrm{L} 2 / 3 \mathrm{SOM}}\left(p=9.3 \times 10^{-4}\right), \mathrm{Ge}_{\mathrm{L} 2 / 3 \mathrm{PV}}>\mathrm{Ge}_{\mathrm{L} 2 / 3 \mathrm{VIP}}\left(p=6.5 \times 10^{-5}\right), \mathrm{Ge}_{\mathrm{L} 2 / 3 \mathrm{PV}}>\mathrm{Ge}_{\mathrm{L} 2 / 3 \mathrm{NPY}}(p=0.0060)$. The following comparisons of inhibitory conductances among cell types were significant (Kruskal-Wallis test, Bonferroni correction): $\mathrm{Gi}_{\mathrm{L} 5 \text { Pyr }}>\mathrm{Gi}_{\mathrm{L} 5 \mathrm{PV}}(p=0.0010), \mathrm{Gi}_{\mathrm{L} 5 \text { Pyr }}>\mathrm{Gi}_{\mathrm{L} 2 / 3 \mathrm{PV}}\left(p=1.1 \times 10^{-4}\right), \mathrm{Gi}_{\mathrm{L} 5 \text { Pyr }}>\mathrm{Gi}_{\mathrm{L}}$ som $(p=5.6 \times$ $\left.10^{-7}\right), \mathrm{Gi}_{\mathrm{L} \text { P Pyr }}>\mathrm{Gi}_{\mathrm{L} 2 / 3 \text { SOM }}\left(p=1.7 \times 10^{-5}\right), \mathrm{Gi}_{\mathrm{L} 5 \text { Pyr }}>\mathrm{Gi}_{\mathrm{L} 2 / 3 \mathrm{VIP}}\left(p=5.4 \times 10^{-4}\right), \mathrm{Gi}_{\mathrm{L} 2 / 3 \text { Pyr }}>\mathrm{Gi}_{\mathrm{L} 5 \mathrm{PV}}(p=0.0013), \mathrm{Gi}_{\mathrm{L} 2 / 3 \text { Pyr }}>\mathrm{Gi}_{\mathrm{L} 2 / 3 \text { PV }}\left(p=5.8 \times 10^{-4}\right), \mathrm{Gi}_{\mathrm{L} 2 / 3 \text { Pyr }}>\mathrm{Gi}_{\mathrm{L} 5 \mathrm{SOM}}(p=1.60 \times$ $\left.10^{-6}\right), \mathrm{Gi}_{\mathrm{L} 2 / 3}$ Pyr $>\mathrm{Gi}_{\mathrm{L} 2 / 3 \text { SOM }}\left(p=2.2 \times 10^{-5}\right), \mathrm{Gi}_{\mathrm{L} 2 / 3 \mathrm{Pyr}}>\mathrm{Gi}_{\mathrm{L} 2 / 3 \mathrm{VIP}}\left(p=4.6 \times 10^{-4}\right)$.

of entorhinal cortex, where virtually the only interneurons that spiked during Up states were FS cells; SOM cells fired at very low rates, whereas no VIP or NPY cells fired any action potentials (Tahvildari et al., 2012). Accordingly, the authors also reported low excitatory and inhibitory conductances in these interneurons. The discrepancies between our barrel cortex data and the entorhinal cortex data of Tahvildari et al. (2012) might reflect differences in experimental conditions or differences in the functional connectivity or excitability of non-FS interneurons in barrel cortex and entorhinal cortex. To distinguish between these possibilities, we prepared and recorded from slices of entorhinal and barrel cortex under identical conditions.

We recorded the Up state activity of pyramidal, PV, SOM, and VIP cells in layer $2 / 3$ of medial entorhinal cortex (the region indicated in Tahvildari et al., 2012) and compared their firing rates and synaptic conductances with cells of similar type in layer $2 / 3$ of barrel cortex (Table 3 ). Both SOM and VIP cells fired at much lower rates in entorhinal cortex than in barrel cortex (Fig. $10 A)$. Indeed, most ( $~ 85 \%)$ of VIP cells in entorhinal cortex fired no action potentials during the Up state, compared with $17 \%$ of VIP cells in barrel cortex. There were no significant differences between the firing rates of PV cells in entorhinal cortex and barrel cortex, but pyramidal cells in entorhinal cortex fired significantly more during Up states than pyramidal cells in barrel cortex. This may be due to the increased levels of activation of non-FS interneurons in barrel cortex. Accordingly, the mean inhibitory conductance of pyramidal cells in barrel cortex during Up states was more than twice that of pyramidal cells in entorhinal cortex 
Table 3. Properties of excitatory and inhibitory neurons in entorhinal cortex ${ }^{a}$

\begin{tabular}{|c|c|c|c|c|c|}
\hline & $\begin{array}{l}\text { L2/3 Pyr } \\
(n=29)\end{array}$ & $\begin{array}{l}\mathrm{L} 2 / 3 \mathrm{PV} \\
(n=20)\end{array}$ & $\begin{array}{l}\mathrm{L} 2 / 3 \\
\text { SOM (NFS) } \\
(n=6)\end{array}$ & $\begin{array}{l}\text { L2/3 } \\
\text { SOM (FS) } \\
(n=9)\end{array}$ & $\begin{array}{l}\mathrm{L} 2 / 3 \mathrm{VIP} \\
(n=21)\end{array}$ \\
\hline $\operatorname{RMP}(\mathrm{mV})$ & $-63.2(2.9)$ & $-64.4(2.9)$ & $-63.3(3.8)$ & $-63.7(4.5)$ & $-63.3(3.6)$ \\
\hline$R_{\text {in }}(M \Omega)$ & $65.0(26.7)$ & $33.3(16.3)$ & 166.6 (99.6) & 49.9 (21.6) & 115.9 (32.4) \\
\hline AP thresh (mV) & $-41.6(5.7)$ & $-42.2(5.4)$ & $-36.3(4.6)$ & $-35.8(5.1)$ & $-42.7(4.0)$ \\
\hline$\tau_{\mathrm{m}}(\mathrm{ms})$ & $16.8(7.0)$ & $4.0(4.2)$ & $22.9(11.5)$ & $6.0(1.2)$ & $10.1(1.8)$ \\
\hline AP half-width (ms) & $0.77(0.2)$ & $0.24(0.06)$ & $0.50(0.1)$ & $0.40(0.09)$ & $0.50(0.7)$ \\
\hline Up firing rate (Hz) & $6.4(7.8)$ & $21.3(38.4)$ & $1.0(1.2)$ & $35.5(32.4)$ & $0.06(0.2)^{* *}$ \\
\hline $\begin{array}{l}\text { Up depolarization } \\
(\mathrm{mV})\end{array}$ & $5.5(2.1)$ & $7.3(2.2)$ & $4.5(2.4)$ & $10.1(2.4)$ & $2.2(1.1)$ \\
\hline$\sigma_{\text {Up }} / \sigma_{\text {Down }}$ & $13.7(13.1)$ & $9.7(3.5)$ & $5.7(2.4)$ & $23.9(19.5)$ & $3.2(1.4)$ \\
\hline$G_{E}(n S)$ & $1.5(1.1)$ & $5.0(3.8)$ & $N A^{*}$ & $N A^{*}$ & $0.3(0.1)$ \\
\hline $\mathrm{G}_{\mathrm{i}}(\mathrm{nS})$ & $1.9(1.4)$ & $1.8(2.6)$ & $N A^{*}$ & $N A^{*}$ & $0.4(0.6)$ \\
\hline
\end{tabular}

Values are mean (SD). RMP, Resting membrane potential; $R_{\text {in }}$ input resistance; AP thresh, action potential threshold; $\tau_{m}$, membrane time constant; AP half-width, action potential half-width; $\sigma_{U p} / \sigma_{\text {Down }}$, normalized membrane potential SD during Up state; $G_{E}$, excitatory conductance; $G_{1}$, inhibitory conductance. $n$ refers to the total number of cells studied.

*NA, Not applicable; NFS SOM cells could not be distinguished from FS SOM cells using Cs-gluconate internal solution.

** Only 2 of 13 VIP cells recorded in entorhinal cortex fired action potentials during the Up state.

(Fig. 10B). Pyramidal cells in barrel cortex also had larger excitatory conductances during Up states than did pyramidal cells in entorhinal cortex. Although the Up state synaptic conductances of PV cells in barrel cortex and entorhinal cortex were similar, VIP cells in barrel cortex exhibited significantly higher excitatory and inhibitory conductances (Fig. 10B). The higher firing rates of non-FS interneurons in barrel cortex are probably due to these larger synaptic conductances rather than to differences in intrinsic excitability. SOM cells in barrel cortex were more excitable than those in entorhinal cortex; resting membrane potential of barrel SOM cells was more depolarized and spike threshold was more hyperpolarized, compared with entorhinal SOM cells $(-59.9 \mathrm{mV}$ vs $-63.3 \mathrm{mV}, p=0.034$ and $-41.8 \mathrm{mV}$ vs $-36.3 \mathrm{mV}$, $p=0.041$, respectively). VIP cells, however, actually had a more hyperpolarized resting membrane potential in barrel cortex than in entorhinal cortex $(-65.7 \mathrm{mV}$ vs $-63.3 \mathrm{mV}, p=0.031)$, but no significant differences in other excitability measures.

An unexpected finding in our recordings from entorhinal cortex was that a majority of recorded cells identified by the tdTomato reporter in the SOM-Cre line (9 of $15=60 \%$ ) exhibited a FS phenotype, whereas the rest exhibited a traditional lowthreshold spiking phenotype (Table 3; Fig. $11 A, B$ ). These FS fluorescent cells in the SOM-tdTomato animal resembled FS PV cells in their spiking behavior to suprathreshold current steps (irregular interspike intervals at near-threshold current stimuli, and high firing rates with little spike-frequency adaptation), passive membrane properties (short membrane time constant), and high firing rate during Up states. For this reason, we divided data from SOM cells in entorhinal cortex into FS and non-FS categories (Table 3). We also do not report synaptic conductances from SOM cells in entorhinal cortex because it was not possible to distinguish between FS and non-FS SOM cells using Csgluconate internal. Although such a dichotomy of behavior in SOM cells in entorhinal cortex was not reported in Tahvildari et al. (2012), those authors used the transgenic GIN mouse line, which only labels a subset of SOM cells (Oliva et al., 2000; Ma et al., 2006) and does not rely on Cre-mediated recombination for cell-type-specific fluorophore expression.

We wondered whether there was overlap of PV and tdTomato expression in the SOM-tdTomato animal in entorhinal cortex. To test this, we performed PV immunohistochemistry in ento-
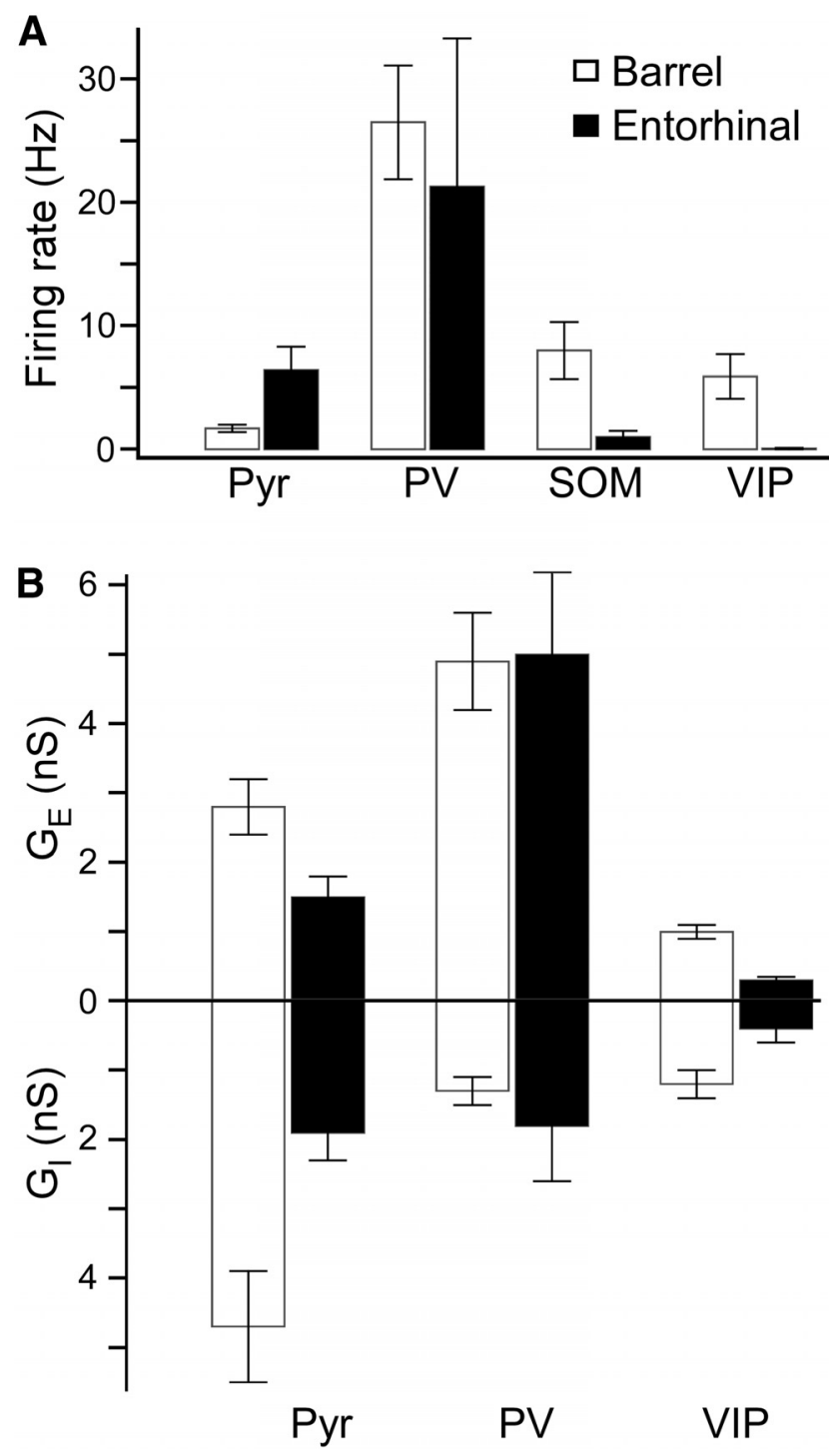

Figure 10. Comparisons of Up states in pyramidal cells and interneurons between barrel cortex and entorhinal cortex. $A$, Comparisons of mean total firing rates in pyramidal cells, PV cells, SOM cells, and VIP cells in L2/3 between barrel cortex and entorhinal cortex. Error bars indicate SEM. The following comparisons were significant (Mann-Whitney test): $R_{\text {Pyr, entorhinal }}>$ $\mathrm{R}_{\text {Pyr, barrel }}(p=0.032), \mathrm{R}_{\text {SOM, entorhinal }}<\mathrm{R}_{\text {SOM, barrel }}(p=0.0070), \mathrm{R}_{\mathrm{VIP} \text {, entorhinal }}<\mathrm{R}_{\mathrm{VIP} \text {, barrel }}$ $(p=0.00029)$. $\boldsymbol{B}$, Comparisons of mean total excitatory and inhibitory conductances in pyramidal cells, PV cells, and VIP cells in L2/3 between barrel cortex and entorhinal cortex. Error bars indicate SEM. The following comparisons were significant (Mann-Whitney test): $\mathrm{G}_{\mathrm{e}, \text { Pyr, entorhinal }}<$

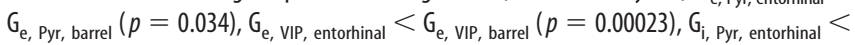
$\mathrm{G}_{\mathrm{i}, \text { Pyr, barrel }}(p=0.0067), \mathrm{G}_{\mathrm{i}}$ VIP, entorhinal $<\mathrm{G}_{\mathrm{i} \text {, VIP, barrel }}(p=0.013)$.

rhinal cortex from SOM-tdTomato mice. We found that the percentage of cells expressing both $\mathrm{PV}$ and tdTomato in the SOM-tdTomato animal was higher in entorhinal cortex compared with barrel cortex (Fig. 11C,D). Whether the PVimmunopositive tdTomato cells in the SOM-tdTomato animal are also truly SOM-positive would require immunohistochemistry for both PV and SOM, which we did not perform. Interestingly, a recent report suggested that PV-immunopositive tdTomato cells in the SOM-tdTomato animal are actually not SOM positive and are, thus, not true SOM cells (Hu et al., 2013). This may also be true of the SOM-tdTomato cells in entorhinal cortex. Another possibility is that a certain fraction of the SOMtdTomato cells in entorhinal cortex we classified as FS may, in- 
A NFS SOM cell (entorhinal cortex)

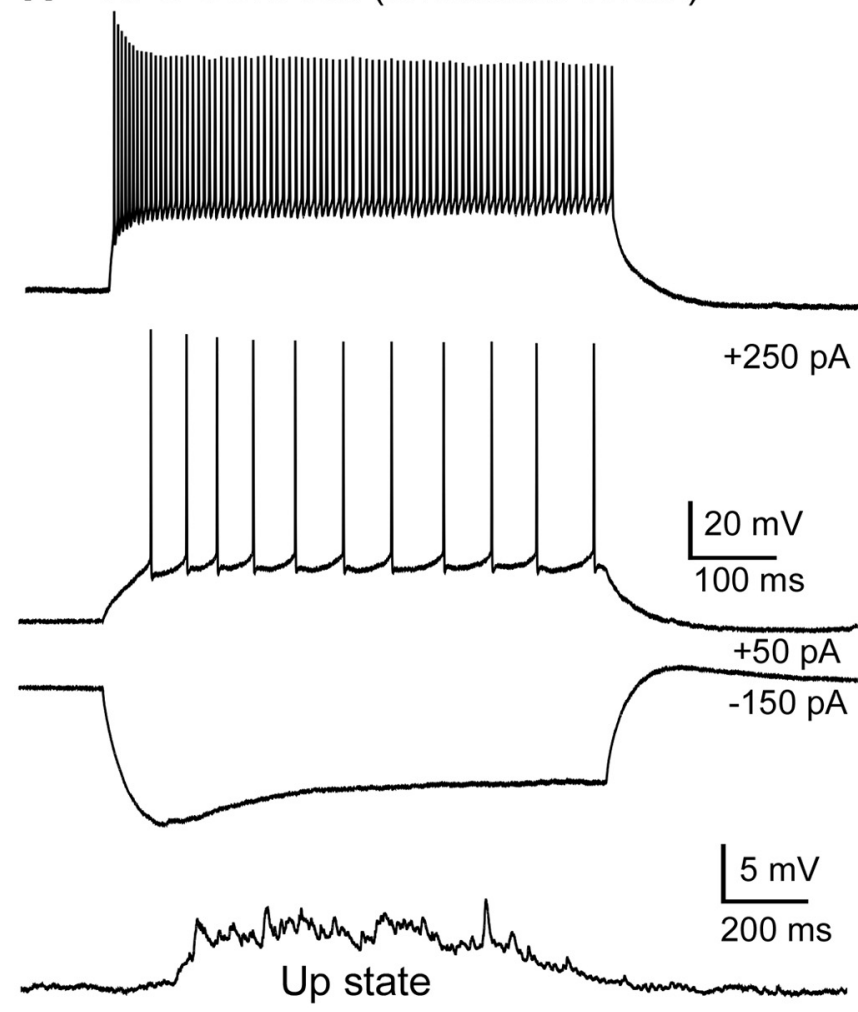

B FS SOM cell (entorhinal cortex)

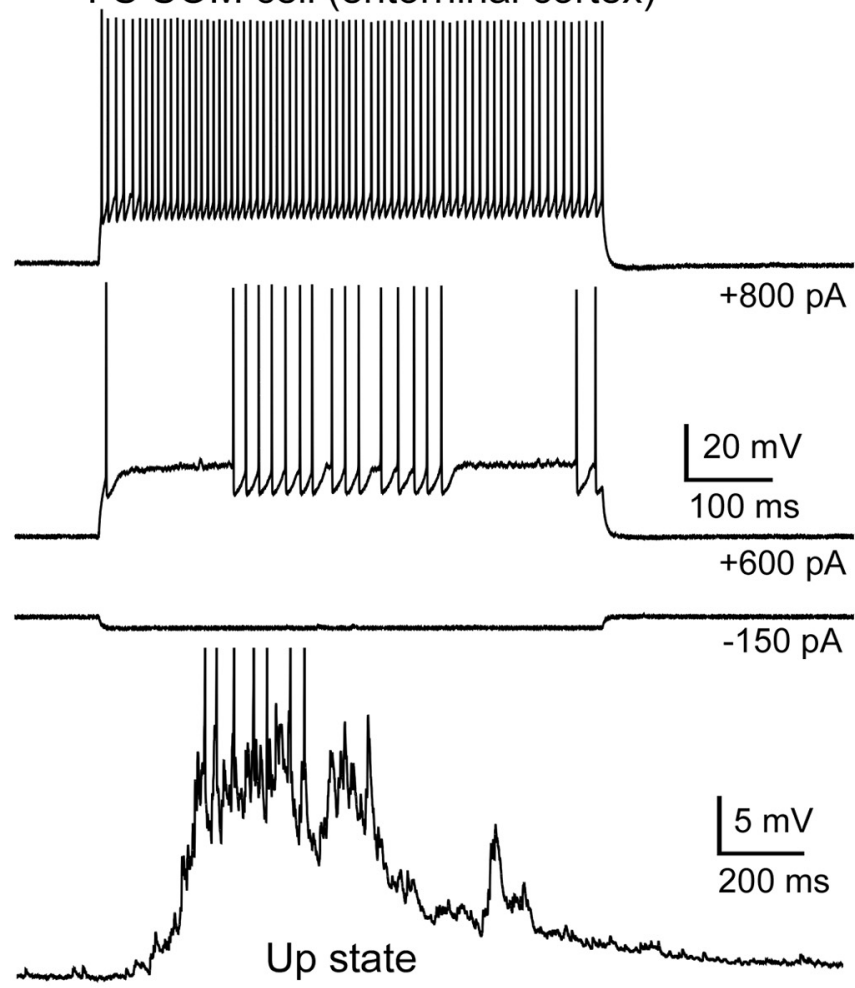

C

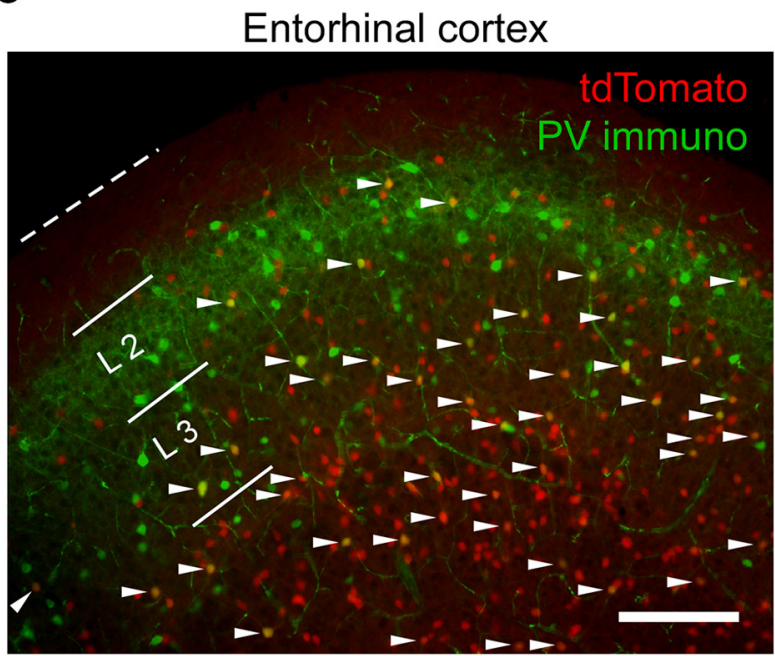

Barrel cortex
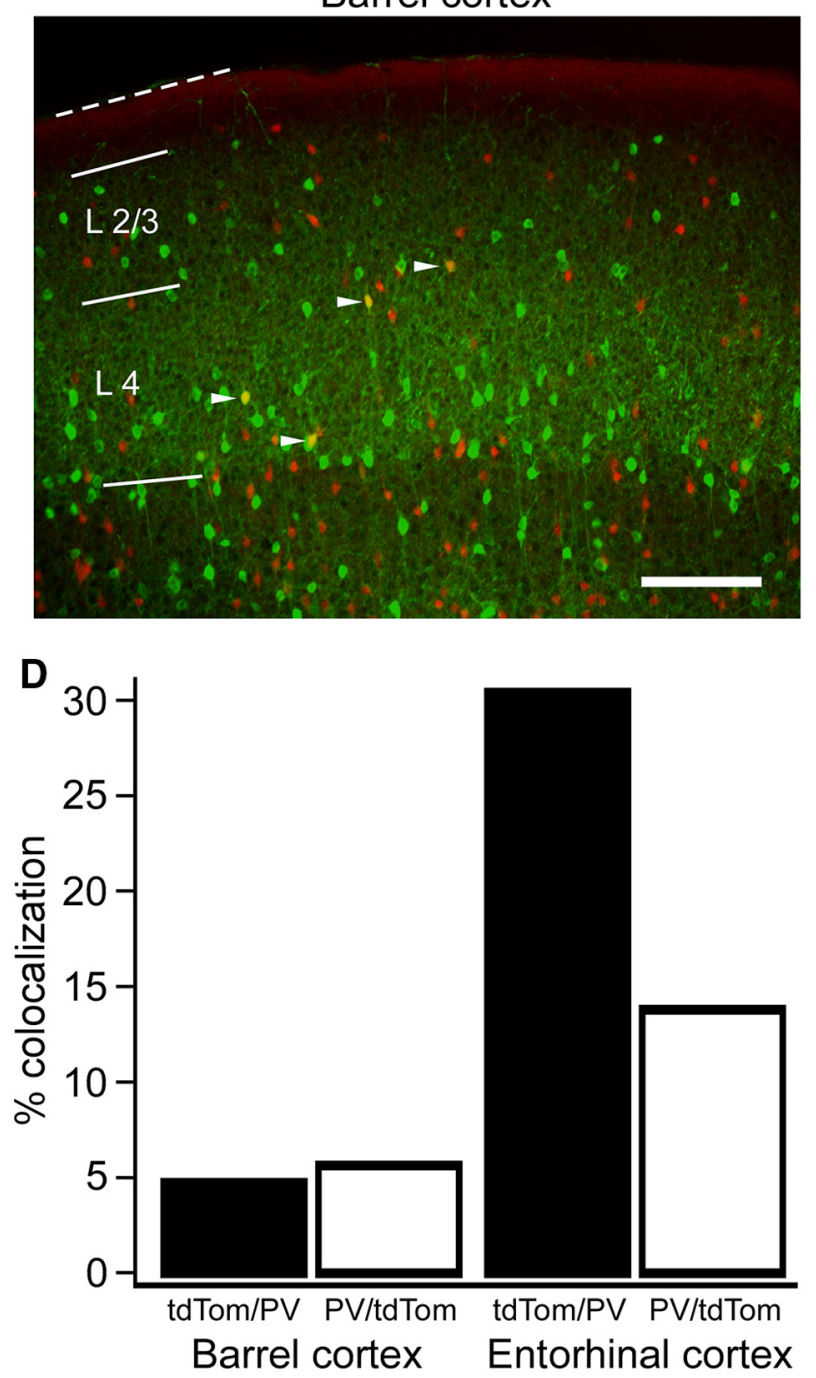

Figure 11. Analysis of fluorescent FS cells in the SOM-tdTomato animal. $\boldsymbol{A}, \boldsymbol{B}$, Voltage traces of non-FS and FS SOM cells (i.e., fluorescent cells in the SOM- tdTomato animal) as evidenced by intrinsic properties and behavior during Up states ( 9 of 15 recorded fluorescent cells had a FS phenotype). Action potentials during the Up state in B are truncated. C, Representative PVimmunostained slices from barrel cortex and entorhinal cortex from the SOM-tdTomato animal. White arrowheads indicate colabeled cells. Note the substantial overlap of PV (green) and tdTomato (red) in entorhinal cortex but minimal overlap in barrel cortex. Scale bars, $200 \mu \mathrm{m}$. D, Percentage colocalization of PV with tdTomato in the SOM-tdTomato animal in barrel cortex and entorhinal cortex ( $n=2$ animals, 21 slices, 549 counted PV cells, 460 counted tdTomato cells, P19, for barrel cortex; $n=2$ animals, 25 slices, 654 counted PV cells, 1441 counted tdTomato cells P19, for entorhinal cortex). 
deed, be SOM-positive, quasi-FS cells, such as those labeled in the transgenic X94 mouse line (Ma et al., 2006).

We conclude that SOM and VIP interneurons are much more active during $U p$ states in barrel cortex than in entorhinal cortex, demonstrating that the functional connectivity of these cells depends on cortical area. We also found that some of the fluorescent cells in the SOM-tdTomato animal exhibited the physiological properties of FS cells. PV immunohistochemistry in the SOMtdTomato animal showed more overlap of PV and tdTomato expression in entorhinal cortex than in barrel cortex.

\section{Discussion}

We characterized the activity of a diverse group of excitatory and inhibitory neurons in barrel cortex during Up states. Our results suggest that, although FS PV cells are the most active, SOM, VIP, and NPY cells are often as active as pyramidal cells. This suggests that all interneuron subtypes in barrel cortex may play a role in regulating Up states.

A neuron's activity during an Up state depends on the convergence, strength, and location of its synaptic inputs, and on its intrinsic excitability as determined by its membrane potential, spike threshold, and input resistance. Our measurements of firing rate and synaptic conductances during Up states provide a picture of the functional connectivity of diverse cell types in barrel cortex.

Layer 5 pyramidal cells reliably spiked during the Up state and received substantial excitatory and inhibitory conductances (Figs. 6 and 9). Although layer 2/3 pyramidal cells also received strong synaptic inputs, they fired at much lower rates, often not reaching threshold. This is consistent with work in intact animals reporting lower spontaneous and sensory-evoked firing rates in layer $2 / 3$ pyramidal cells than in deeper layers (de Kock et al., 2007; de Kock and Sakmann, 2009; O'Connor et al., 2010). The inhibitory conductances of pyramidal cells in layer $2 / 3$ were comparable with those of layer 5 , so the lower firing rates of the layer $2 / 3$ cells are probably due to their reduced excitability.

Despite their relatively low input resistance and high spike threshold (Table 2), PV interneurons were by far the most active cell type during Up states. This is due to their strong excitatory input (Fig. 9), which is consistent with data from paired recordings of FS and pyramidal cells in barrel cortex that show largeamplitude unitary PSPs, and high connection and release probabilities (Gibson et al., 1999; Beierlein et al., 2003; Avermann et al., 2012). The membrane properties of PV cells also cause less attenuation of high-frequency input (Hasenstaub et al., 2005). The abundant spiking of PV cells suggests they provide the majority of the inhibitory regulation during Up states.

Other interneuron subtypes spiked frequently during Up states. Compared with neighboring pyramidal cells, layer 5 SOM cells fired just as rapidly, whereas SOM and VIP cells in layer 2/3 fired even faster (Fig. 6). NPY cells also fired, although at low rates and primarily at the onset of the Up state. Although unitary excitatory synaptic inputs onto SOM cells in layers 4 and $2 / 3$ are weak, with low release probabilities when activated slowly (Beierlein et al., 2003, Reyes et al., 1998), SOM cells received substantial excitatory inputs during the Up state (Fig. 9), perhaps due to convergence of pyramidal cell input. The unitary properties of synapses onto and from VIP and NPY cells have not been well characterized, but our measurements imply that these cells receive synaptic conductances similar in magnitude to those of SOM cells.

The firing rates of interneurons and the magnitude of inhibitory conductances, especially in pyramidal cells, suggest that Up states in barrel cortex are dominated by inhibition. Inhibition often rules cortical activity. Sensory responses are heavily dominated by inhibition (Borg-Graham et al., 1998; Haider et al., 2013). Furthermore, selective activation of pyramidal cells actually recruits inhibition more strongly than excitation (Mateo et al., 2011). Our results show that not only is inhibition strong in evoked responses in cortex, but also in the emergent pattern of synaptic activity characterizing the Up state. Reports about the relative contributions of excitation and inhibition to spontaneous cortical activity in vivo are inconsistent, with some sources citing a balance of these conductances (Haider et al., 2006), some citing stronger inhibition (Rudolph et al., 2007), and others citing stronger excitation (Waters and Helmchen, 2006). These discrepancies could be due to differing functional connectivity of excitatory and inhibitory cells, which may vary by cortical area, age, species, or behavioral state.

We found that inhibition peaks near the beginning of the Up state, and subsequently decreases in all cell types (Fig. 9). This decrease in inhibition after an early peak is likely due to the highly depressing nature of PV-cell synapses. The synaptic depression of PV-cell synapses could also account for the lack of a strong relationship between the time-dependent firing rate of PV cells and the evolution of inhibitory conductance in pyramidal cells (e.g., the firing rate of layer $2 / 3 \mathrm{PV}$ cells in Fig. $6 \mathrm{~B}$ and the inhibitory conductance of layer $2 / 3$ pyramidal cells in Fig. $9 B$ ). It seems unlikely that the termination of the Up state is controlled by synaptic inhibition because neither a gradual buildup nor a sudden increase in inhibition near the end of the Up state occurs. The mechanisms that terminate spontaneous active states are unclear. Some have suggested that activity-dependent hyperpolarizing conductances (e.g., $\mathrm{g}_{\mathrm{K}-\mathrm{Ca}}$ and $\mathrm{g}_{\mathrm{K}-\mathrm{Na}}$ ) reduce excitability late in the Up state (Sanchez-Vives and McCormick, 2000; Compte et al., 2003). Others have observed that the Up-to-Down state transition is actually more synchronized among neurons than the Down-to-Up state transition (Volgushev et al., 2006), suggesting that a network mechanism, perhaps synaptic inhibition, is necessary for Up state termination (Chen et al., 2012).

Because each interneuron subtype in barrel cortex spiked during Up states, each may provide inhibitory regulation of network activity. Most of this regulation undoubtedly comes from PV cells, the most active subtype. Because PV cells synapse near the soma of pyramidal cells, they probably control spike timing of these targets during the Up state. PV cell firing might also be the primary cause of membrane potential variance during the Up state (Hasenstaub et al., 2005; Destexhe, 2010). Thus, one potential role of PV cells is to maintain the Up state by enhancing membrane potential variance.

SOM cells receive facilitating excitatory input (Reyes et al., 1998; Gibson et al., 1999; Beierlein et al., 2003; Silberberg and Markram, 2007), and so it has been hypothesized that they control the termination of Up states; a buildup of excitatory input could increase their probability of firing late in a period of activation (Melamed et al., 2008; Fanselow and Connors, 2010; Krishnamurthy et al., 2012). Substantial facilitation onto SOM cells depends on presynaptic firing rates $>\sim 20 \mathrm{~Hz}$, yet pyramidal cells fire more slowly than this during Up states (Fig. 6). We observed that SOM cells fire most during the beginning of Up states, so it is unlikely they control Up state termination. What role might SOM cells play in Up states? Many SOM cells synapse on distal apical dendrites and may help to regulate dendritic electrogenesis important for the burst-firing of some layer 5 pyramidal cells (Larkum et al., 1999) that are crucial for Up state initiation and propagation (Chauvette et al., 2010; Beltramo et al., 2013). A recent report showed that, during Up and Down 
states in the waking animal, the membrane potential fluctuations of SOM cells are actually anti-correlated with those of neighboring pyramidal cells (Gentet et al., 2012). We found, in contrast, that membrane potential fluctuations of SOM cells, other interneuron subtypes, and pyramidal cells were all correlated (Fig. 8). This suggests that intracortical network mechanisms are not sufficient for the anticorrelated membrane potential fluctuations of SOM cells during active network states in vivo but might depend on additional neuromodulatory inputs (Fanselow et al., 2008).

We also observed that VIP cells fired almost as much as SOM cells in barrel cortex. Recent evidence suggests that VIP cells synapse primarily on SOM cells while avoiding pyramidal cells (Lee et al., 2013; Pfeffer et al., 2013). Thus, during spontaneous network activity such as Up states, VIP cells might disinhibit the distal dendrites of pyramidal cells by inhibiting SOM cells.

Expression of NPY in interneurons of barrel cortex is largely nonoverlapping with the other major neurochemical markers (Lee et al., 2010). Some have suggested that NPY identifies neurogliaform cells (Tahvildari et al., 2012; Chittajallu et al., 2013) which, perhaps uniquely, inhibit neighboring cells through $\mathrm{GABA}_{\mathrm{B}}$ receptors (Tamás et al., 2003) that mediate slow inhibition (Connors et al., 1988). Pharmacological studies have shown that $\mathrm{GABA}_{\mathrm{B}}$-mediated inhibition controls the duration of $\mathrm{Up}$ states (Mann et al., 2009). A GABA $\mathrm{B}_{\mathrm{B}}$ effect in the termination of Up states would not have been detected in our conductance measurements because QX-314 blocks $\mathrm{GABA}_{\mathrm{B}}$ receptor-activated potassium channels (Nathan et al., 1990).

The high level of activation of non-FS interneurons that we recorded during Up states in barrel cortex is strikingly absent in entorhinal cortex, which has been reported previously (Tahvildari et al., 2012) and which we verified independently. Whereas VIP and SOM cells fire at rates comparable to pyramidal cells and receive substantial synaptic inputs during Up states in barrel cortex, SOM cells in entorhinal cortex fire very sparsely and VIP cells are almost completely silent. In agreement with Tahvildari et al. (2012), we found that PV cells were virtually the only active interneuron subtype in entorhinal cortex. This difference between the two areas indicates not only a notable specificity in the functional connectivity of interneurons in different cortical areas, but also that inhibition during active states in barrel cortex, but not entorhinal cortex, is distributed along the somatodendritic axis of pyramidal cells because both soma-targeting PV cells and dendrite-targeting SOM cells are active. Because somatic and dendritic inhibition is thought to have different effects on the response properties of pyramidal cells (Lovett-Barron et al., 2012), the transformation of synaptic input into spiking activity is also likely to be different between barrel and entorhinal cortex.

\section{References}

Agmon A, Connors BW (1991) Thalmocortical responses of mouse somatosensory (barrel) cortex in vitro. Neuroscience 41:365-379. CrossRef Medline

Avermann M, Tomm C, Mateo C, Gerstner W, Petersen CC (2012) Microcircuits of excitatory and inhibitory neurons in layer $2 / 3$ of mouse barrel cortex. J Neurophysiol 107:3116-3134. CrossRef Medline

Beierlein M, Gibson JR, Connors BW (2003) Two dynamically distinct inhibitory networks in layer 4 of the neocortex. J Neurophysiol 90:29873000. CrossRef Medline

Beltramo R, D’Urso G, Dal Maschio M, Farisello P, Bovetti S, Clovis Y, Lassi G, Tucci V, De Pietri Tonelli D, Fellin T (2013) Layer-specific excitatory circuits differentially control recurrent network dynamics in the neocortex. Nat Neurosci 16:227-234. CrossRef Medline

Borg-Graham LJ, Monier C, Frégnac Y (1998) Visual input evokes transient and strong shunting inhibition in visual cortical neurons. Nature 393: 369-373. CrossRef Medline
Braitenburg V, Shuz A (1998) Cortex: statistics and geometry of neuronal connectivity. New York: Springer.

Chagnac-Amitai Y, Luhmann HJ, Prince DA (1990) Burst generating and regular spiking layer 5 pyramidal neurons of rat neocortex have different morphological features. J Comp Neurol 296:598-613. CrossRef Medline

Chauvette S, Volgushev M, Timofeev I (2010) Origin of active states in local neocortical networks during slow sleep oscillation. Cereb Cortex 20: 2660-2674. CrossRef Medline

Chen JY, Chauvette S, Skorheim S, Timofeev I, Bazhenov M (2012) Interneuron-mediated inhibition synchronizes neuronal activity during slow oscillation. J Physiol 590:3987-4010. CrossRef Medline

Chittajallu R, Pelkey KA, McBain CJ (2013) Neurogliaform cells dynamically regulate somatosensory integration via synapse-specific modulation. Nat Neurosci 16:13-15. CrossRef Medline

Compte A, Sanchez-Vives MV, McCormick DA, Wang XJ (2003) Cellular and network mechanisms of slow oscillatory activity $(<1 \mathrm{~Hz})$ and wave propagations in a cortical network model. J Neurophysiol 89:2707-2725. CrossRef Medline

Connors BW, Gutnick MJ, Prince DA (1982) Electrophysiological properties of neocortical neurons in vitro. J Neurophysiol 48:1302-1320. Medline

Connors BW, Malenka RC, Silva LR (1988) Two inhibitory postsynaptic potentials, and GABAA and GABAB receptor-mediated responses in neocortex of rat and cat. J Physiol 406:443-468. Medline

Cruikshank SJ, Lewis TJ, Connors BW (2007) Synaptic basis for intense thalamocortical activation of feedforward inhibitory cells in neocortex. Nat Neurosci 10:462-468. CrossRef Medline

de Kock CP, Sakmann B (2009) Spiking in primary somatosensory cortex during natural whisking in awake head-restrained rats is cell-type specific. Proc Natl Acad Sci U S A 106:16446-16450. CrossRef Medline

de Kock CP, Bruno RM, Spors H, Sakmann B (2007) Layer- and cell-typespecific suprathreshold stimulus representation in rat primary somatosensory cortex. J Physiol 581:139-154. CrossRef Medline

Destexhe A (2010) Inhibitory "noise.” Front Cell Neurosci 4:9. CrossRef Medline

Destexhe A, Hughes SW, Rudolph M, Crunelli V (2007) Are corticothalamic 'up' states fragments of wakefulness? Trends Neurosci 30:334-342. CrossRef Medline

Fanselow EE, Connors BW (2010) The roles of somatostatin-expressing (GIN) and fast spiking inhibitory interneurons in UP-DOWN states of mouse neocortex. J Neurophysiol 104:596-606. CrossRef Medline

Fanselow EE, Richardson KA, Connors BW (2008) Selective, statedependent activation of somatostatin-expressing inhibitory interneurons in mouse neocortex. J Neurophysiol 100:264-2652. CrossRef Medline

Fishell G, Rudy B (2011) Mechanisms of inhibition within the telencephalon: "where the wild things are." Annu Rev Neurosci 34:535-567. CrossRef Medline

Gentet LJ, Kremer Y, Taniguchi H, Huang ZJ, Staiger JF, Petersen CC (2012) Unique functional properties of somatostatin-expressing GABAergic neurons in mouse barrel cortex. Nat Neurosci 15:607-612. CrossRef Medline

Gibson JR, Beierlein M, Connors BW (1999) Two networks of electrically coupled inhibitory interneurons in neocortex. Nature 402:75-79. CrossRef Medline

Goldman-Rakic PS (1995) Cellular basis of working memory. Neuron 14: 477-485. CrossRef Medline

Haider B, Duque A, Hasenstaub AR, McCormick DA (2006) Neocortical network activity in vivo is generated through a dynamic balance of excitation and inhibition. J Neurosci 26:4535-4545. CrossRef Medline

Haider B, Duque A, Hasenstaub AR, Yu Y, McCormick DA (2007) Enhancement of visual responsiveness by spontaneous local network activity in vivo. J Neurophysiol 97:4186-4202. CrossRef Medline

Haider B, Häusser M, Carandini M (2013) Inhibition dominates sensory responses in the awake cortex. Nature 493:97-100. CrossRef Medline

Hájos N, Mody I (2009) Establishing a physiological environment for visualized in vitro brain slice recordings by increasing oxygen supply and modifying aCSF content. J Neurosci Methods 183:107-113. CrossRef Medline

Hájos N, Ellender TJ, Zemankovics R, Mann EO, Exley R, Cragg SJ, Freund TF, Paulsen O (2009) Maintaining network activity in submerged hippocampal slices: importance of oxygen supply. Eur J Neurosci 29:319327. CrossRef Medline

Hasenstaub A, Shu Y, Haider B, Kraushaar U, Duque A, McCormick DA (2005) 
Inhibitory postsynaptic potentials carry synchronized frequency information in active cortical networks. Neuron 47:423-435. CrossRef Medline

Hasenstaub A, Sachdev RN, McCormick DA (2007) State changes rapidly modulate cortical neuronal responsiveness. J Neurosci 27:9607-9622. CrossRef Medline

Hefti BJ, Smith PH (2000) Anatomy, physiology, and synaptic responses of rat layer $\mathrm{V}$ auditory cortical cells and effects of intracellular GABA(A) blockade. J Neurophysiol 83:2626-2638. Medline

Hu H, Cavendish JZ, Agmon A (2013) Not all that glitters is gold: off-target recombination in the somatostatin-IRES-cre mouse line labels a subset of fast spiking interneurons. Front Neural Circuits 7:195. CrossRef Medline

Kasper EM, Larkman AU, Lübke J, Blakemore C (1994) Pyramidal neurons in layer 5 of the rat visual cortex: I. Correlation among cell morphology, intrinsic electrophysiological properties, and axon targets. J Comp Neurol 339:459-474. CrossRef Medline

Kawaguchi Y, Kubota Y (1997) GABAergic cell subtypes and their synaptic connections in rat frontal cortex. Cereb Cortex 7:476-486. CrossRef Medline

Krishnamurthy P, Silberberg G, Lansner A (2012) A cortical attractor network with Martinotti cells driven by facilitating synapses. PLoS One 7:e30752. CrossRef Medline

Larkum ME, Zhu JJ, Sakmann B (1999) A new cellular mechanism for coupling inputs arriving at different cortical layers. Nature 398:338-341. CrossRef Medline

Le Bon-Jego M, Yuste R (2007) Persistently active, pacemaker-like neurons in neocortex. Front Neurosci 1:123-129. CrossRef Medline

Lee S, Hjerling-Leffler J, Zagha E, Fishell G, Rudy B (2010) The largest group of superficial neocortical GABAergic interneurons expresses ionotropic serotonin receptors. J Neurosci 30:16796-16808. CrossRef Medline

Lee S, Kruglikov I, Huang ZJ, Fishell G, Rudy B (2013) A disinhibitory circuit mediates motor integration in the somatosensory cortex. Nat Neurosci 16:1662-1670. CrossRef Medline

Lovett-Barron M, Turi GF, Kaifosh P, Lee PH, Bolze F, Sun XH, Nicoud JF, Zemelman BV, Sternson SM, Losonczy A (2012) Regulation of neuronal input transformations by tunable dendritic inhibition. Nat Neurosci 15: 423-430. CrossRef Medline

Luczak A, Barthó P, Harris KD (2009) Spontaneous events outline the realm of possible sensory responses in neocortical populations. Neuron 62:413425. CrossRef Medline

Ma Y, Hu H, Berrebi AS, Mathers PH, Agmon A (2006) Distinct subtypes of somatostatin-containing neocortical interneurons revealed in transgenic mice. J Neurosci 26:5069-5082. CrossRef Medline

Mann EO, Kohl MM, Paulsen O (2009) Distinct roles of GABAa and GABAb receptors in balancing and terminating persistent cortical activity. J Neurosci 29:7513-7518. CrossRef Medline

Markram H, Toledo-Rodriguez M, Wang Y, Gupta A, Silberberg G, Wu C (2004) Interneurons of the neocortical inhibitory system. Nat Rev Neurosci 5:793-807. CrossRef Medline

Maruoka N, Murata T, Omata N, Fujibayashi Y, Waki A, Yoshimoto M, Yano R, Yonekura Y, Wada Y (2001) Greater resistance and lower contribution of free radicals to hypoxic neurotoxicity in immature rat brain compared to adult brain as revealed by dynamic changes in glucose metabolism. Dev Neurosci 23:412-419. CrossRef Medline

Mateo C, Avermann M, Gentet LJ, Zhang F, Deisseroth K, Petersen CC (2011) In vivo optogenetic stimulation of neocortical excitatory neurons drives brain-state-dependent inhibition. Curr Biol 21:1593-1602. CrossRef Medline

Melamed O, Barak O, Silberberg G, Markram H, Tsodyks M (2008) Slow oscillations in neural networks with facilitating synapses. J Comput Neurosci 25:308-316. CrossRef Medline

Nathan T, Jensen MS, Lambert JD (1990) The slow inhibitory postsynaptic potential in rat hippocampal CA1 neurones is blocked by intracellular injection of QX-314. Neurosci Lett 110:309-313. CrossRef Medline

O'Connor DH, Peron SP, Huber D, Svoboda K (2010) Neural activity in barrel cortex underlying vibrissa-based object localization in mice. Neuron 67:1048-1061. CrossRef Medline

Oliva AA Jr, Jiang M, Lam T, Smith KL, Swann JW (2000) Novel hippocampal interneuronal subtypes identified using transgenic mice that express green fluorescent protein in GABAergic interneurons. J Neurosci 20: 3354-3368. Medline

Petersen CC, Hahn TTG, Mehta M, Grinvald A, Sakmann B (2003) Interaction of sensory responses with spontaneous depolarization in layer $2 / 3$ barrel cortex. Proc Natl Acad Sci U S A 100:13638-13643. CrossRef Medline

Pfeffer CK, Xue M, He M, Huang ZJ, Scanziani M (2013) Inhibition of inhibition in visual cortex: the logic of connections between molecularly distinct interneurons. Nat Neurosci 16:1068-1076. CrossRef Medline

Poulet JF, Petersen CC (2008) Internal brain state regulates membrane potential synchrony in barrel cortex of behaving mice. Nature 454:881-885. CrossRef Medline

Reyes A, Lujan R, Rozov A, Burnashev N, Somogyi P, Sakmann B (1998) Target-cell-specific facilitation and depression in neocortical circuits. Nat Neurosci 1:279-285. CrossRef Medline

Reynolds JH, Pasternak T, Desimone R (2000) Attention increases sensitivity of V4 neurons. Neuron 26:703-714. CrossRef Medline

Rudolph M, Pospischil M, Timofeev I, Destexhe A (2007) Inhibition determines membrane potential dynamics and controls action potential generation in awake and sleeping cat cortex. J Neurosci 27:5280-5290. CrossRef Medline

Sanchez-Vives MV (2012) Spontaneous rhythmic activity in the adult cerebral cortex in vitro. In: Isolated central nervous system circuits (Ballanyi K, ed), pp 263-284. New York: Springer.

Sanchez-Vives MV, McCormick DA (2000) Cellular and network mechanisms of rhythmic recurrent activity in neocortex. Nat Neurosci 3:10271034. CrossRef Medline

Seamari Y, Narváez JA, Vico FJ, Lobo D, Sanchez-Vives MV (2007) Robust off- and online separation of intracellularly recorded up and down cortical states. PLoS One 2:e888. CrossRef Medline

Shu Y, Hasenstaub A, Badoual M, Bal T, McCormick DA (2003a) Barrages of synaptic activity control the gain and sensitivity of cortical neurons. J Neurosci 23:10388-10401. Medline

Shu Y, Hasenstaub A, McCormick DA (2003b) Turning on and off recurrent balanced cortical activity. Nature 423:288-293. CrossRef Medline

Silberberg G, Markram H (2007) Disynaptic inhibition between neocortical pyramidal cells mediated by Martinotti cells. Neuron 53:735-746. CrossRef Medline

Simon A, Oláh S, Molnár G, Szabadics J, Tamás G (2005) Gap-junctional coupling between neurogliaform cells and various interneuron types in the neocortex. J Neurosci 25:6278-6285. CrossRef Medline

Steriade M, Nuñez A, Amzica F (1993) a novel $(<1 \mathrm{~Hz})$ oscillation of neocortical neurons in vivo: depolarizaing and hyperpolarizing components. J Neurosci 13:3252-3265. Medline

Sun YJ, Kim YJ, Ibrahim LA, Tao HW, Zhang LI (2013) Synaptic mechanisms underlying functional dichotomy between intrinsic bursting and regular spiking neurons in auditory cortical layer 5. J Neurosci 33:53265339. CrossRef Medline

Tahvildari B, Wölfel M, Duque A, McCormick DA (2012) Selective functional interactions between excitatory and inhibitory cortical neurons and differential contribution to persistent activity of the slow oscillation. J Neurosci 32:12165-12179. CrossRef Medline

Tamás G, Lorincz A, Simon A, Szabadics J (2003) Identified sources and targets of slow inhibition in the neocortex. Science 299:1902-1905. CrossRef Medline

Taniguchi H, He M, Wu P, Kim S, Paik R, Sugino K, Kvitsiani D, Fu Y, Lu J, Lin Y, Miyoshi G, Shima Y, Fishell G, Nelson SB, Huang ZJ (2011) A resource of Cre driver lines for genetic targeting of GABAergic neurons in cerebral cortex. Neuron 71:995-1013. CrossRef Medline

Volgushev M, Chauvette S, Mukovski M, Timofeev I (2006) Precise longrange synchronization of activity and silence in neocortical neurons during slow-wave sleep. J Neurosci 26:5665-5672. CrossRef Medline

Waters J, Helmchen F (2006) Background synaptic activity is sparse in neocortex. J Neurosci 26:8267-8277. CrossRef Medline

Wehr M, Zador AM (2003) Balanced inhibition underlies tuning and sharpens spike timing in auditory cortex. Nature 426:442-446. CrossRef Medline

Wester JC, Contreras D (2012) Columnar interactions determine horizontal propagation of recurrent network activity in neocortex. J Neurosci 32:5454-5471. CrossRef Medline

Wilson CJ, Groves PM (1981) Spontaneous firing patterns of identified spiny neurons in the rat neostriatum. Brain Res 220:67-80. CrossRef Medline

Yu J, Ferster D (2010) Membrane potential synchrony in primary visual cortex during sensory stimulation. Neuron 68:1187-1201. CrossRef Medline 